\title{
Un emprendimiento minero "al estilo inglés": materialidades, cuerpos y disciplina en Catamarca (Argentina), siglo XIX
}

\section{An "english style" mining company: materialities, bodies and discipline in Catamarca (Argentina), $19^{\text {th }}$ century}

Lorena B. Rodríguez ${ }^{1,2}$ (D) https://orcid.org/0000-0002-2986-9848

${ }^{1}$ Consejo Nacional de Investigaciones Científicas y Técnicas. Buenos Aires, ARGENTINA.

Email: rodriguezlo@hotmail.com

${ }^{2}$ Universidad de Buenos Aires. Buenos Aires, ARGENTINA.

\section{Resumen}

A mediados del siglo XIX se desarrollaron varios proyectos mineros en el oeste de la provincia de Catamarca (Argentina), dedicados principalmente a la explotación de cobre. En ese contexto, la Casa Lafone era presentada por su dueño -entre otras cosas- como un emprendimiento de "estilo inglés", diferenciado del resto por la tecnología empleada y por el modo en que se organizaban las faenas y diferentes aspectos relativos a la vida de los trabajadores. En este artículo buscamos caracterizar el funcionamiento de dicho establecimiento minero poniendo el foco en el modo en que habitaron, trabajaron y circularon las personas como resultado de las reconfiguraciones espaciales y arquitectónicas y, en consecuencia, de tiempos, ritmos, tipos y formas de trabajo. Proponemos que esas reconfiguraciones constituyeron formas sutiles pero no menos potentes de control y disciplinamiento de la mano de obra que, junto a otras acciones, implicaron grandes cambios e impactos sobre el paisaje y los recursos y principalmente sobre la vida de las personas que allí vivieron y trabajaron.

Palabras clave: minería, disciplinamiento, arquitectura, trabajadores. 


\begin{abstract}
In the mid- $19^{\text {th }}$ century, several mining projects were developed in the west of Catamarca province (Argentina), mainly dedicated to the exploitation of copper. In that context, the Casa Lafone was presented by its owner -among other things- as an "English-style" company, differentiated from the rest by the technology used and by the way in which the tasks and different aspects related to the workers' lives were organized. In this paper we seek to characterize the operation of this mining establishment by focusing on the way in which people lived, worked and circulated as a result of spatial and architectural reconfigurations and, consequently, of times, rhythms, types and forms of work. We propose that these reconfigurations constituted subtle but no less powerful forms of workers control and discipline that, together with other actions, implied major changes and impacts on the landscape and resources and mainly on the life of the people who lived and worked there.
\end{abstract}

Keywords: mining, discipline, architecture, workers.

Recibido: 3 diciembre 2019. Aceptado: 7 mayo 2020 
There is the Restauradora Mine which produces twice or three times as much ore as all Mr. Carranza's Mines put together, and is worked in real English mining style, with proper adits, shafts, tramways and every other appliance necessary to work economically. Captain John Jory, a Cornish man, has laid out the village very advantageously, and there is even a church and school-house for the workmen on the place, to which Mr. Carranza's men and their families can go when they choose, or he lets them. ${ }^{1}$

\section{Introducción}

La cita que encabeza este trabajo fue escrita en 1883 por Samuel Lafone Quevedo, dueño de un emprendimiento minero de cobre en el oeste de la actual provincia de Catamarca (Argentina) que funcionó durante la segunda mitad del siglo XIX. Más allá del evidente conflicto que Lafone parecía tener con Adolfo Carranza (otro empresario minero de la zona), el texto transcripto nos deja entrever varias cuestiones que sirven como disparadores de este artículo. Por un lado, el modo diferencial en que según Lafone eran trabajadas sus minas, en "verdadero estilo inglés", con tecnología apropiada para un funcionamiento económico. Por otra parte, aunque en vinculación con el punto anterior, nos muestra que la forma de trabajo no era lo único que importaba. Para que el proyecto resultara viable se necesitaba un profundo cambio en el estilo de vida de los trabajadores que, como en otros casos ya estudiados, incursionaba más allá del ámbito laboral (instituciones como la escuela o la Iglesia serán clave en ese sentido). Así, los proyectos mineros que se desarrollaron en la zona desde mediados del siglo XIX -y el de la Casa Lafone en particular, sobre el cual aquí nos centraremos- implicaron grandes transformaciones e impactos de diversas escalas en el paisaje, los recursos y principalmente sobre la vida de las personas que estuvieron -de algún modo- a ellos vinculadas.

Estos cambios, por supuesto, no fueron exclusivos del proyecto de Lafone. Muy por el contrario, existe una vasta y rica historiografía respecto a distintos emprendimientos mineros latinoamericanos del siglo XIX que ofrecen una buena base general de referencia y comparación desde la cual abordar nuestro caso de estudio. En tal sentido, por ejemplo, los trabajos de Deustua $(1995,2009,2011)$ y Contreras $(1988,2015)$ para Perú nos permiten delinear algunas de las características que adquirió la actividad minera en la región, sus auges y declives, durante el período republicano y, en especial, hacia la segunda mitad del siglo XIX cuando, como consecuencia de la demanda internacional, se abriera el mercado para una nueva minería, ya no de metales preciosos como el oro y la plata sino de metales industriales, entre otros, como el cobre. Esta minería supuso cambios tecnológicos, mayor inversión de capitales y planteó el desafío de reclutar mano de obra suficiente para las nuevas formas de trabajo. Los estudios ya señalados para el caso peruano analizan este tema pero, dado que la "escasez de brazos" era una queja generalizada de los empresarios decimonónicos, es posible encontrar referencias sobre esta cuestión en investigaciones para otros espacios, como el boliviano (Rodríguez Ostria, 2001) o el chileno (Ortega Martínez, 2005, 2009; Venegas Valdebenito, 2006, 2007), que describen las distintas estrategias que fueron implementándose por parte de los empresarios (enganches, endeudamientos, aumentos de salarios, articulación del sistema minero con el rural) con el objeto de captar trabajadores.

Ahora bien, como sostiene Sierra Álvarez $(1984,1985,1990)$ en sus estudios sobre la minería asturiana de la segunda mitad del siglo XIX, en las etapas iniciales del proceso de industrialización

1 The Standard, 25 de enero de 1883. Colección The Standard. Universidad de San Andrés. El destacado es nuestro. 
el problema no solo era atraer y fijar a una población de origen campesino a las nuevas labores, sino también adaptar a los trabajadores al nuevo ámbito productivo (o incluso -como el autor dice- construir un "obrero sońado", ideal); es decir, disciplinarlos. Desde una perspectiva foucaultiana, que entiende a los "cuerpos" como objeto y blanco de poder, ${ }^{2}$ Sierra Álvarez describe cómo bajo el supuesto de que esos cuerpos eran maleables, los patrones asturianos implementaron detallados programas de disciplinamiento cuyo éxito se basaría en su carácter abarcante; esto es, "el control de la existencia toda del trabajador, de su espacio y de su tiempo” (Sierra Álvarez, 1990, p. 92). Así, las configuraciones espaciales, la construcción de paisajes industriales, demarcados materialmente a partir de una arquitectura capaz de crear y mantener las relaciones de poder (Zarankin, 2003), ocuparán un lugar central en la economía disciplinaria no solo en el ámbito productivo, del trabajo, sino también -como sostiene Sierra Álvarez (1990) - sobre el trabajador mismo, sus modos de vivir, pensar y sentir (el tiempo del no-trabajo).

Desde el marco planteado, recuperando y entablando diálogos específicos con la bibliografía disponible para el espacio latinoamericano y, especialmente, con la investigación de Delfino et al. (2014) para el distrito de Capillitas, provincia de Catamarca, en este trabajo buscamos caracterizar el funcionamiento del establecimiento minero de la Casa Lafone. A través de un corpus documental heterogéneo que incluye informes técnicos, descripciones de viajeros, planos, censos poblacionales, correspondencia inédita, fotos y dibujos, entre otros, pondremos el foco en el modo en que habitaron, trabajaron y circularon las personas como resultado de las reconfiguraciones espaciales, arquitectónicas, de tiempos, ritmos, tipos y formas de trabajo, propios de los emprendimientos industriales del período, así como del modelado de nuevos hábitos sociales (por supuesto, no siempre totalmente impuestos). Proponemos que esas reconfiguraciones constituyeron formas más sutiles pero no menos potentes de control y disciplinamiento de la mano de obra que buscaron reducir la fuerza de los cuerpos en términos políticos de obediencia y maximizarlos en términos económicos de utilidad (Foucault, 2002, p. 142).

A tal fin, en primer lugar, ofreceremos una contextualización general del período y el espacio de estudio para centrarnos luego en algunas características de la minería del oeste de la actual provincia de Catamarca, especialmente de la zona de Andalgalá, y también del emprendimiento de la Casa Lafone. En segundo lugar, describiremos el modo en que esta empresa, tanto en lo relativo a la extracción como al procesamiento del mineral, reconfiguró el paisaje y la espacialidad a través de las instalaciones propias del laboreo minero y de otras arquitecturas asociadas (habitaciones para obreros, casa administración, iglesia, escuela, etc.). Finalmente, nos enfocaremos en las personas que vivieron y trabajaron para dicha empresa con el objeto de analizar las formas en que las materialidades funcionaron, junto a un conjunto específico de prácticas como mecanismos de disciplinamiento. Para cerrar, sintetizamos los principales aspectos del artículo, dejando en consideración posibles líneas de trabajo a profundizar.

2 Foucault (2002) propone que, desde el siglo XVII y a lo largo de la historia, los cuerpos comenzaron a ser foco de atención, con el objeto de poder someterlos, utilizarlos, transformarlos, docilizarlos minuciosa e ininterrumpidamente a través de diferentes métodos que él reconoce como "disciplinas". La "invención" de esta anatomía política, dice, se ha impuesto casi siempre para responder a exigencias de coyuntura; por ejemplo, una innovación industrial. Sin embargo, se inscribe en unas transformaciones generales que definen la adscripción de los cuerpos a una nueva "microfísica" del poder. 


\section{Contextualización general de la minería en Andalgalá (Catamarca) y de la Casa Lafone durante la segunda mitad del siglo XIX}

Hacia mediados del siglo XIX comenzó el proceso de fortalecimiento de Argentina como una nación, pues se produjo el afianzamiento institucional de la república unificada (Romero, 1993). Impuesto el "orden", entendido -entre otras cosas- como un nuevo marco de organización social relacionado con el nuevo perfil del sistema económico capitalista, se abría la posibilidad al "progreso" en tanto ideal a partir del cual la sociedad desarrollaría sus fuerzas productivas (Oszlak, 1982). El período se caracterizó así por estar sentado en los lineamientos de un orden liberal que buscaba la inserción del país en la cada vez más integrada economía mundial, fundamentalmente a partir de un modelo agroexportador cuyo epicentro estaba en la zona de la Pampa húmeda y cuya implementación impactaría de maneras diferentes en las economías regionales: algunas provincias de regiones como el Noroeste Argentino (NOA) con el azúcar y de Cuyo con el vino, por ejemplo, lograron posteriormente negociar condiciones especiales para vincularse al modelo, aunque orientadas al mercado interno (Campi y RichardJorba, 2004).

Bonaudo (1999) señala que el liberalismo en el que se pretendió refundar la sociedad del siglo XIX tenía como uno de sus desafíos dar contenido a la idea de "progreso". En ese marco, el ramo minero se representará como una gran oportunidad; especialmente para provincias como Catamarca o La Rioja que -según destacan Rojas y Wagner (2017) - constituían espacios periféricos no solo en comparación con el desarrollo histórico minero de países como Chile y Bolivia, sino también porque las políticas de modernización agropecuarias que se desplegarían en el litoral, Tucumán o Mendoza en la segunda mitad del siglo XIX no se aplicarían en aquellos territorios. En efecto, aunque desde la década de 1850 Catamarca logró una mejora en las actividades productivas y comerciales, entre otras cosas de la mano de la potencialidad de la producción minera, pronto fue evidente que -en el contexto de la orientación agroganadera de exportación- esta actividad no llegaría a despegar completamente (Alvero, 2013), quedando Catamarca verdaderamente marginada del contexto nacional hacia fines del siglo XIX (Osatinsky, 2015).

De todos modos, promediando dicho siglo, las expectativas cifradas en la minería catamarqueña eran altas y estaban puestas especialmente en la zona de Capillitas; un rico depósito de minerales de cobre, con leyes variables de oro y plata, ubicado en el oeste de la provincia a $3000 \mathrm{msnm}$, en el actual departamento de Andalgalá. En la zona, desde el Período Colonial, se habían desarrollado algunos proyectos mineros (Rodríguez, 2015) que, al igual que en otros casos (por ejemplo, el asiento de San Antonio del Nuevo Mundo en Lípez, Bolivia, estudiado por Gil Montero, 2014), habían registrado o bien una corta vida o bien intermitencias a lo largo del tiempo. En este último sentido, sabemos que alrededor de la década de 1760 las explotaciones andalgalenses se habían activado y eran promisorias, a tal punto que luego de una visita minera a la zona las autoridades decidieron fundar una villa (denominada de San Carlos) para que se convirtiera en un pueblo minero (Alonso et al., 2018). En 1825, Miguel Díaz de la Peña (titular del Mayorazgo de Huazán) retomó en la zona las labores que se habían desactivado, restaurando las instalaciones y los molinos con el objetivo de procesar el mineral -por trituración y amalgamación- e hizo traer para tal fin a 28 mineros ingleses (De Moussy, 1860). De todos modos, no será sino hasta mediados del siglo XIX que la explotación minera alcanzará mayor intensidad. De Moussy (1860) señala que por aquellos años una importante cantidad 
de personas denunciaron minas y comenzaron su explotación. En sus palabras: "quà la fin de 1854 il y avait déjà cent quarante-trois mines dénoncées et dont la concession avait été faite, et qu'en juillet 1857 ce nombre sélevait à deux cent soixante dix'huit" (De Moussy, 1860, p. 415). ${ }^{3}$

Una visita realizada a las minas de Andalgalá en 1859 por el ingeniero agrimensor Plácido Aimón ${ }^{4}$ da cuenta del crecimiento de la actividad en la zona. Para la fecha en que se hace la inspección, Aimón señala que se habían pedido unas 341 minas de oro $(\mathrm{Au})$, plata $(\mathrm{Ag})$, cobre $(\mathrm{Cu})$ y níquel $(\mathrm{Ni})$. A lo largo de los años irán explotándose nuevas minas y vetas de la mano de viejos y nuevos mineros, aunque se mantendrán como las más importantes algunas de las asentadas en la sierra de Capillitas: mina La Rosario de Anselmo Segura, Adolfo Carranza y Samuel y Mardoqueo Molina y mina La Restauradora de Samuel Fisher Lafone que -tal como advierte Espeche (1875) en su descripción de la provincia de Catamarca- serán las que produzcan y procesen mayor cantidad de metal y nucleen a la mayor cantidad de trabajadores del ramo.

Cabe destacar que Samuel Fisher Lafone, empresario de origen inglés, se había radicado inicialmente en Buenos Aires hacia 1825 para pronto trasladarse a Montevideo. Allí desarrolló múltiples actividades y negocios (comercio de exportación de cueros, instalación de saladero, compra y venta de tierras) hasta que finalmente se dedicó a la minería (Mariani, 2009). En los primeros años de la década de 1850 formó una sociedad con Marcelino Augier y Manuel Malbrán para reactivar las minas catamarqueńas de Capillitas, adquiriendo en 1856 la mina Restauradora a los señores Porto, Madrid y Figueroa (Lafone Quevedo, 2010 [1894]; Furlong, 1964; Catalano, 2004). En los primeros tiempos fundió metales en lejanos ingenios: de la mina Santa Clara en el ingenio de Ampajango (en sociedad con Augier) y de la mina Restauradora en el denominado Victoria, ubicados ambos en el departamento de Santa María (a 55 y $85 \mathrm{~km}$ de los yacimientos, respectivamente) en donde contaba con abundante madera, fundamental combustible (Salvatierra, 1965; González, 2014). Más tarde la empresa de Fisher Lafone adquirió en el departamento de Andalgalá una propiedad denominada Balde de la Carpintería o de Don Fabián, que su hijo y futura cabeza del emprendimiento -Samuel Lafone Quevedo- ${ }^{5}$, rebautizó como Pilciao. ${ }^{6}$ A ese lugar (perteneciente a la provincia fitogeográfica de monte), a partir de 1860, se trasladaría definitivamente la fundición de los minerales de La Restauradora, más cercano a los yacimientos de Capillitas (Figura 1) y con acceso al bosque de algarrobos que proveería de combustible a la empresa para procesar el mineral en los hornos de reverbero que, como veremos más adelante, llegaron a ser nueve.

Justamente por esa época (1859), Samuel Lafone Quevedo -que acababa de regresar de su formación en Cambridge (Master of Arts) - se hizo cargo de la empresa familiar; aunque quien

3 "[...] que a fines de 1854 ya había ciento cuarenta y tres minas denunciadas, cuya concesión se había hecho, y que en julio de 1857 este número ascendía a doscientos setenta y ocho" (traducción nuestra).

4 Archivo Histórico de Catamarca (AHC), Sección Gobierno, Carpeta 17, Relación de la visita a las minas por el Ing. Agrimensor Plácido Aimón, 1859.

5 Samuel Lafone Quevedo nació en Uruguay (Montevideo) el 28 de febrero de 1835. Aunque uruguayo por nacimiento, pasó gran parte de su vida en la provincia de Catamarca. Allí, entre emprendimientos mineros y viajes de exploración, comenzó la tarea de colectar datos arqueológicos, lingüísticos y folclóricos, constituyéndose posteriormente en un reconocido académico del campo antropológico argentino. Existen numerosos trabajos que aportan al conocimiento de esta figura y sus diferentes aristas y perfiles. Al respecto véase, por ejemplo, Boman, 1922; Cabrera, 1943; Márquez Miranda, 1958; Furlong, 1964; Peña de Bascary, 1978; Haber y Delfino, 1995-96; Farro, 2013, entre otros.

6 "Yo soy el autor de la ortografía Pilciao, cuando restauré á este pago su antiguo nombre. La propiedad fué adquirida bajo el nombre de Balde de la Carpintería ó de Don Fabián, que así se llamaba nuestro vendedor" (Lafone Quevedo, 1898, p. XLI). 


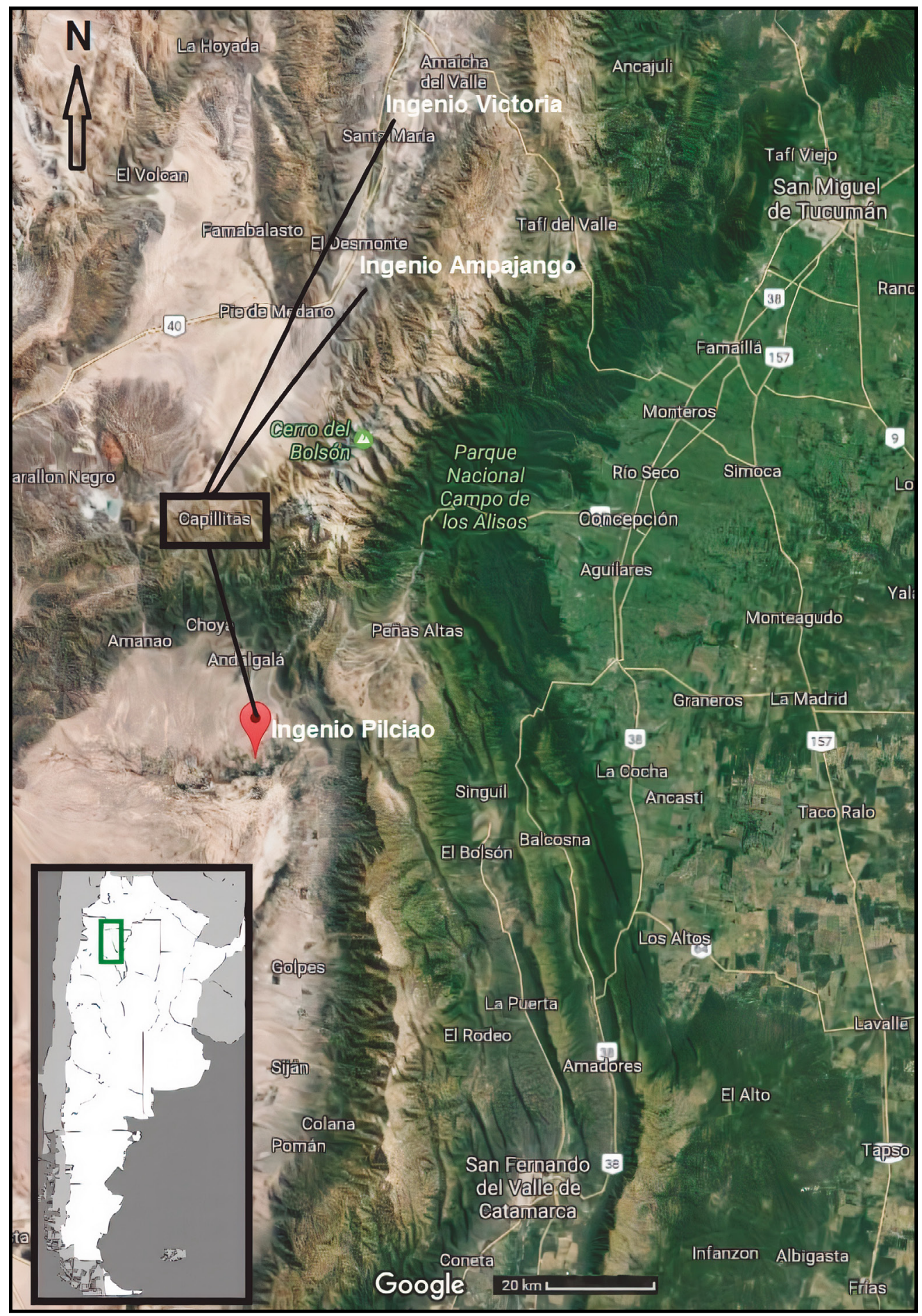

Figura 1. Mapa de ubicación general de las localidades mencionadas en el texto sobre cartografía actual. Fuente: Google Maps (2019). 
efectivamente habría estado al frente de la administración y organización del proyecto durante los primeros años habría sido Juan Heller ${ }^{7}$ (al menos hasta 1872 cuando Lafone Quevedo se instaló definitivamente en Pilciao), mientras que Federico Schickendantz ${ }^{8}$ se habría encargado de la parte técnica. Este sería el período de mayor producción y procesamiento de cobre de la empresa, alcanzando su punto más alto en 1870 con 10800 quintales, para luego fluctuar en sus valores con tendencia sostenida a la baja en los años siguientes (Lafone Quevedo y Schickendantz, 1881, p. 101).

Según señala el propio Lafone Quevedo (1894), a principios de la década de 1890 la minería en Capillitas se encontraba en franca crisis. Entre las principales causas que aquejaron el devenir de su empresa señala la depreciación del valor internacional del cobre. En efecto, como describe Ortega Martínez (2009), la caída de los precios se inició en 1873 y continuó prácticamente sin interrupciones hasta 1896 afectando no solo la producción de cobre en Chile (que es el ejemplo sobre el que dicho autor se centra), sino también de diversos países y regiones, como el caso que aquí analizamos. A ese factor externo, Lafone agrega el desvío de trabajadores como resultado del paralelo desarrollo de la industria azucarera en la vecina provincia de $\mathrm{Tu}$ cumán y el consecuente encarecimiento de los jornales para el ramo minero. En términos más específicos, describe el problema del transporte. La falta de buenos caminos, la ausencia de vías férreas y los altos costos impuestos por los arrieros hacían cada vez menos rentable el negocio (Lafone Quevedo, 1894). Por supuesto, este tampoco era un inconveniente exclusivo de su emprendimiento, pues - como ha mostrado Gil Montero (2014) - si bien para algunas faenas la tecnología decimonónica había permitido reducir la cantidad de mano de obra necesaria, el rubro del acarreo (del mineral o de la leña), en particular en zonas a donde el ferrocarril no había llegado, continuaba siendo el más oneroso. Otro elemento a considerar, no señalado por Lafone pero sí por el técnico de la empresa, es el del agotamiento de los bosques de algarrobo para fundir el metal. Este recurso, considerado por muchos actores de la época como infinito, fue utilizado de manera descontrolada e irresponsable en los distintos emprendimientos mineros de la zona, no solo devastando los algarrobales y afectando la ecología local, sino también aumentando los costos para las empresas (entre otras cosas, al tener que trasladar constantemente las instalaciones para fundir en zonas próximas a los nuevos recursos forestales) y, por ende, contribuyendo a su declive (Schickentdantz, 1874).

En definitiva, hacia la década de 1890, los factores descriptos coadyuvaron para que el emprendimiento de Lafone llegara a su fin. Así, luego de más de 30 años en funcionamiento, esta compañía dejó de producir y procesar mineral en el ingenio de Pilciao. En 1902, una minera de capital inglés -la "Capillitas Copper Company"-adquirió todas las minas de la zona y se hizo cargo de los antiguos ingenios (Alderete, 2004). Comenzaría entonces una nueva etapa en la historia de la minería de Catamarca, aunque su futuro inmediato tampoco sería promisorio pues a los pocos años los trabajos serían abandonados.

7 Juan Heller Johanssen, nació en 1828 en Schleswig-Holstein (Dinamarca) y fue oficial de marina mercante, profesión por la cual llegó a Uruguay. Allí conoció a Fisher Lafone, entablando luego una relación laboral que lo llevaría al emprendimiento catamarqueño y a partir de la cual trabaría una larga relación con Samuel Lafone Quevedo. Hacia 1872 se estableció en Tucumán y fue uno de los socios propietarios (también junto a Lafone) del ingenio azucarero de La Trinidad (Peña de Bascary, 1976).

8 Federico Schickendantz nació en Baviera Renana (El Palatinado) el 15 de febrero de 1837. Se había formado como químico y en calidad de metalurgo fue contratado alrededor de 1861 por la empresa Lafone para desempeñarse en la parte técnica. Además de los aportes que hizo a esta empresa, realizó estudios de la flora local, fue docente en el Colegio Nacional y director de la Escuela Agronómica de Tucumán, entre otras muchas tareas (Peña de Bascary, 1980, 2014). 


\section{El paisaje y las materialidades: espacios reconfigurados}

Sin duda, la explotación minera implicó grandes cambios. Entre otros aspectos, el paisaje -entendido no como (o solo) una entidad física ya dada, sino como una construcción social, cargada de significado; esto es, como un "producto socio-cultural creado por la objetivación, sobre el medio y en términos espaciales, de la acción social tanto de carácter material como imaginario" (Criado Boado, 1999)-, comenzó a transformarse de la mano de la implementación de lógicas y técnicas decimonónicas de explotación europeas. En el emprendimiento minero de la Casa Lafone, a diferencia de otros casos en donde la producción del mineral tenía dos fases que dependían de compañías diferentes, ${ }^{9}$ las instalaciones de la empresa articulaban, por un lado, la extracción de los minerales y, por otro, su procesamiento. Como describe González (2014), se trataba de una instalación fija (la mina) con otra móvil (el ingenio). Esta imagen del ingenio móvil (o transhumante, como dirá Salvatiera, 1965) refleja, como anticipamos en el apartado anterior, uno de los más importantes impactos producidos por este tipo de minería: el desmonte de los bosques locales, cuyo agotamiento requería de un traslado constante de los ingenios en búsqueda del indispensable recurso. Estos dos componentes del sistema (la mina y el ingenio) se unían gracias a una extensa red de caminos y de transporte, basada en energía animal (principalmente mulas).

En cuanto a las minas, y tal como señalan Delfino et al. (2014) en su estudio sobre la explotación de cobre en Capillitas, se reemplazó el antiguo sistema de "rajos" a cielo abierto y chiflones por un nuevo diseño de laboreo a través de galerías y piques. Este sistema, según testimonios de la época, ${ }^{10}$ permitía un mejor aprovechamiento de las vetas así como un mayor volumen de producción, aunque requería de un importante nivel de inversión: rieles en galerías, guinches en piques, vigas y herrajes, ruedas hidráulicas, bombas que poco a poco se harían visibles en el paisaje local, en un -según Lafone- "verdadero estilo inglés". ${ }^{11}$ Lamentablemente no disponemos, por el momento, de abundante información escrita sobre el diseño arquitectónico general asociado a la mina La Restauradora o de cómo se distribuían otros edificios de quienes allí trabajaban. Tampoco se han realizado abordajes arqueológicos detallados en el sitio que, por otra parte, ha sido fuertemente impactado por la actividad minera de la primera mitad del siglo XX. De todos modos, los estudios realizados en la zona por Delfino et al. (2014) sugieren que La Restauradora pudo haber compartido algunas características arquitectónicas similares a otras minas que ellos sí han podido analizar (p.e., minas La Grande, La Rosario, San Salvador).

9 Contreras (1988), por ejemplo, describe cómo en Cerro de Pasco (sierra central peruana) la producción de plata durante el siglo XIX se realizaba a través de empresas mineras y empresas de refinación, siendo muy pocas las empresas que controlaban ambas fases.

10 Planos subterráneos de la mina La Restauradora y detalles del tipo de explotación pueden verse en Rickard (1869), Espeche (1875) y Hoskold (1889). En general, los informes de estos especialistas destacan a La Restauradora como la mina de mayor riqueza de la zona, así como por el modo en que se trabajaba. Rickard, por ejemplo, escribía que La Restauradora era "la mina de más importancia y riqueza en la Provincia. Se ve por el plano que acompaño que los trabajos son muy bien dirijidos, y la economía y ciencia aplicadas con mucho provecho" (1869, p. 120). Hoskold, por su parte, sostenía que "[e]l socavón practicado en La 'Restauradora' es el mejor que he visto en este país y sin dudas es el más largo de la República” (1889, p. 157).

11 En varias oportunidades Lafone insistía en distinguir este modo de trabajo de sistema inglés: "La mina se trabaja por el sistema inglés con piques y galerías con sus testeros correspondientes; el metal se iza por un pique maestro en el cual hay una vía lignea inclinada, con carros y su malacate a mula; las galerías principales también tienen su tren-vía y zorras a burro. El metal, una vez puesto en la cancha o patio de la mina, es liquidado por peones vigilados por un mayordomo" (Lafone Quevedo, 1877; citado en Furlong, 1964, p. 48). 
Entre ellas, estos autores mencionan: la intencionalidad de una permanencia sostenida y una planificación cuidada materializadas por el eje bocamina-riel-canchamina, conectado a su vez a una vía de transporte (caminos); una lógica de organización espacial con una concentración arquitectónica que implica al mismo tiempo una división horizontal de funciones (laboreo, reparación de herramientas, habitaciones, corrales, cocina...) y una división vertical correspondiente a las jerarquías laborales (obreros vs. capataces y propietarios).

De los puntos mencionados por estos autores nos interesa centrarnos en algunas cuestiones. Por un lado, queremos detenernos en el tema de las habitaciones o viviendas de los trabajadores que para Delfino et al. (2014) diferían radicalmente de las lógicas habitacionales propias de la vida campesina. Las diferentes estructuras que ellos analizan y que asocian a espacios residenciales -como parte de las instalaciones de las empresas- se caracterizan por el diseño de "tipo cuartel". Esta configuración, en la que pequeńas habitaciones adosadas se comunicaban a un espacio público, reducía al mínimo la privacidad de las personas, constituyéndose en un dispositivo más de disciplinamiento y vigilancia. En el inventario de los bienes de la familia Lafone realizado en 1901 se registraron en la parte baja de la mina La Restauradora, entre otras cosas, "16 cuartitos para peones", para los cuales no se detallan dimensiones ni características específicas. No sabemos pues para quiénes estaban destinados estos cuartitos o quiénes los habitaron efectivamente, pero bien podrían responder a la lógica disciplinaria descripta. ${ }^{12} \mathrm{El}$ registro de otros "cuartos" de mayores dimensiones o con funciones específicas ("un cuarto sala $3.70 \times 9 \times 2.5 \ldots$ dividido con tres tabiques", "un cuarto habitación $3 \times 4.35 \times 2.5$ ", un "cuarto escritorio en la parte alta de las minas $3.6 \times 5.6 \times 2.5$ ") ${ }^{13}$ podría estar indicando diferencias y rangos laborales (p.e., estar destinados a alojar al personal administrativo o jerárquico).

Ahora bien, más allá de la funcionalidad o características específicas de estos "cuartitos para peones", ${ }^{14}$ los documentos disponibles nos permiten hacer foco sobre un aspecto acerca del que aún no se ha llamado la atención. Ya para un período temprano algunas fuentes mencionan que se había formado una "placilla" en el mineral de La Restauradora y que para 1880 se había trasladado al pie del cerro formando una nueva "villita" denominada "placilla de San Manuel". ${ }^{15}$ Unos ańos después, refiriéndose a esta última placilla, Lafone insistía en cuánto habían mejorado las condiciones habitacionales en la zona, al punto de ser las nuevas casas dignas para hospedarlo. En sus propias palabras:

12 Meléndez (2016), en su investigación sobre el desarrollo del emprendimiento de Mina Dal, El Alto, Catamarca (1930-1990), describe cómo - desde un primer momento- la empresa proyectó el alojamiento de los obreros en el campamento en viviendas "tipo cuartel", prefigurando así un perfil ideal de trabajador: soltero y disponible a tiempo completo. Las entrevistas realizadas por la autora a quienes trabajaron y vivieron en la mina le permiten sostener que, al calor de la intensificación de la producción, nuevos trabajadores llegaron al lugar y se establecieron con sus familias (alquilando incluso los cuartos diseñados para los solteros), no solo transgrediendo la norma de la empresa sino también introduciendo modificaciones sobre el diseño industrial.

13 AHC, Sucesorios, Caja 129, año 1901. Lafone Fisher, Samuel y Quevedo, María, fs. 22 r. y 23 v.

14 Sierra Álvarez (1984) sostiene que la estrategia patronal en Asturias en la segunda mitad del XIX respecto al problema de la vivienda de los trabajadores se regía por algunos principios; entre ellos, el de separar a las familias obreras de los obreros solteros, destinando para estos últimos cuarteles o casas de huéspedes. Tal vez esta fuera la situación respecto a los “cuartitos para peones” mencionados. Más datos son necesarios aún para poder avanzar en ese sentido.

15 Archivo del Obispado de Catamarca (AOC), Andalgalá, Expte. "Erección de una iglesia en la Mina Restauradora en Andalgalá, 1865 y Erección de otra capilla en San Manuel en Capillitas 1882”. Agradezco al Prof. Mario Daniel Vera el acceso y la consulta de este archivo. 
[...] por muchos años las chozas en que vivieron los mineros, peones y patrones, en nada se diferenciaba de las ratoneras en que acostumbraban vivir los descendientes de los Calchaquíes, y que, como dijimos ántes, mas bien eran harneros que casas; pero en estos últimos ańos se ha levantado la Placilla de San Manuel, al pié del cerro de las Capillitas, no muy léjos de los hornillos ya citados, y en la mejor de las casas del lugar entré á descansar (Lafone Quevedo, 1888, p. 54).

De esta cita, que es sumamente rica para analizar, nos enfocaremos por ahora en el término de "placilla" que allí figura. Buena parte de los estudios sobre las placillas las han descripto como nucleamientos habitacionales de características urbanas, espontáneos o autogenerados, que emergían junto a los minerales como espacios marginales y/o de descompresión social y en donde los vicios (especialmente el alcohol y el juego) se convertían en contrapuntos que fomentaban la destrucción de la disciplina de los "campamentos mineros" (Salazar, 1984; Illanes, 2003). Nuevas lecturas proponen comprender las placillas desde una perspectiva temporal a partir de la cual poder constatar variaciones en el concepto. El trabajo de Godoy Orellana (2015a) muestra que las placillas tardocoloniales o aquellas de la primera mitad del siglo XIX poco tienen que ver con placillas como la de Cachinal o de Esmeralda (Atacama), conformadas en las últimas décadas del siglo XIX como resultado -y con mayor injerencia- de la presencia estatal en la zona. La placilla de Capillitas, la de San Manuel en particular, no parece responder solo a una configuración espontánea y tampoco a un diseño de total impronta estatal, pero sí a la voluntad del empresario particular de "ordenar" un espacio en sintonía con un claro propósito "civilizatorio". Ya el Censo de 1869, por ejemplo, registró a la población del mineral de Capillitas como espacio "urbano" (Distrito $2^{\circ}$ ) que supo contar con una escuela (seguro, al menos, desde 1873) ${ }^{16}$ y una capilla ${ }^{17}$ (la primera erigida oficialmente en 1865 y luego refundada en 1882 al ser trasladada a San Manuel). ${ }^{18}$ Una parte de la cita de Lafone que encabeza este trabajo, ${ }^{19}$ seguramente referida a esta última placilla, confirma pues que su configuración no fue espontánea sino resultado de un diseño planificado por parte de la empresa.

Otro aspecto de impacto a considerar es el tema de los caminos y el constante transitar por ellos que debieron haber transformado profundamente el paisaje local. Según Espeche "los caminos para el mineral de Capillitas son los más importantes de este departamento, por su tráfico i buen estado" (1875, p. 324), algunos de los cuales habían sido construidos por la empresa Lafone y otros por la compañía Carranza-Molina. Se trataba de caminos de arrias pero que habían costado a estas empresas (y seguían costando debido al alto mantenimiento que demandaban) importantes cantidades de dinero. Entre las cartas que le escribe Juan Heller

16 En un Informe del presidente de la Comisión de Escuelas de 1873 al Inspector Nacional se indicaba que en la "Escuela Particular del Mineral": "Esta escuela subsiste solo por el patriotismo de algunos de los empleados de la empresa [Lafone], que enseña gratis i por el ausilio que le prestan los empresarios, ha dado buen resultado, educando 40 personas entre los niños i adultos" (García Aguilera, 1873, p. 192).

17 "A un tiro de fusil de esta antigualla, se hallan la capilla y escuela pertenecientes a la Placilla, ambas costeadas por los dueños de la mina Restauradora” (Lafone Quevedo, 1888, p. 60).

18 AOC, Andalgalá, Expte. "Erección de una iglesia en la Mina Restauradora en Andalgalá, 1865 y Erección de otra capilla en San Manuel en Capillitas 1882”. Resulta interesante agregar, en línea con el propósito civilizador de la empresa, que el pedido que hace Lafone al obispo para que se otorgue licencia a la nueva capilla se justificaba, entre otras cosas, en que también "el Sr. Carranza baja su faena al mismo punto de San Manuel, y que se halla este más inmediato a las vecinas estancias, cuyos habitantes podrían acudir a oír misa sin tener que encumbrarse en el cerro, como hasta aquí".

19 "El Captain John Jory, un hombre de Cornualles, ha trazado el pueblo de manera muy ventajosa, e incluso hay una iglesia y una escuela para los trabajadores en el lugar”. The Standard, 25 de enero de 1883. Colección The Standard. Universidad de San Andrés. Traducción nuestra. 
(administrador del emprendimiento Lafone) a su dueño, uno de los temas que causa preocupación es justamente el de los caminos. ${ }^{20}$ No debemos olvidar las características de la escarpada geografía y el clima de la zona, así como las enormes distancias que había entre las minas y los ingenios ${ }^{21}$ (por no hablar de la distancia que luego debía recorrer el mineral para salir a exportación vía Córdoba por el puerto de Rosario o el de Buenos Aires). En el diseño de esos trayectos debía considerarse también el hecho de contar en ellos con abundantes pastos y agua para la importante cantidad de animales que se encargaban del acarreo del mineral (Espeche contabilizó para el año 1873 unas 1200 mulas) así como de los víveres para los mineros, las herramientas, la pólvora, etcétera.

Respecto al ingenio de Pilciao, que -como ya señalamos- desde 1860 comenzó a procesar el mineral extraído de Capillitas, disponemos de mayor información. En principio, la transformación se había iniciado con el desmonte de algarrobos para emplazar las instalaciones del ingenio que lógicamente se había acrecentado con el correr de los años, ya que la madera extraída se utilizaba como combustible para la fundición en los hornos de reverbero. ${ }^{22}$ Poco a poco, el viejo bosque había dado paso a la construcción de la infraestructura propia del ingenio. Existen varias descripciones del mismo pues fue visitado por viajeros, técnicos y amigos de Lafone. Una de esas caracterizaciones es la que hace el naturalista inglés Ernest White, que recorrió la zona en la década de 1880:

Through giant gates we rode into the large square wherein nine enormous furnaces
with their capacious maws, stand ready to belch forth their vulcanic blasts. On either
side are large open sheds for ore stamping and other purposes; buildings for butchers,
bakers, carpenters and smiths, all alive with artisans, stores, a school, a church in
process of building and lastly a large rambling dweling for the manager. All these
structures, forming together a miniature Saltaire, are erected with as light materials
as possible, for the establishment is nomadic, depending upon fuel and fodder, the
twin sovereings that absolutely determine its locality: no surprise therefore need be
entertained why the smelting works should be so far distant from the mines, especially
as the furnaces, when in full operation, consume as much as thirteen or fourteen

20 Se trata este de un interesante corpus documental inédito y poco conocido: las cartas que enviaba Juan Heller al dueńo de la Casa Lafone u otros agentes, que se encuentra depositado en el Archivo Histórico de Tucumán y que se ha catalogado como "Juan Heller. Cartas del Libro Copiador". En este corpus, como acabamos de señalar, uno de los temas recurrentes es el problema de los caminos. Por ejemplo: "Metal sigue viniendo, no mucho a causa de la lluvia que nos ha cortado el camino en muchas partes; dice Don Diego que el temporal ha sido muy grande otra vez en los cerros", "Camino. Hoy se va Benigno para componerlo; dicen que está muy malo en partes” (Pilciao, 21 de febrero y 8 de marzo de 1869, fs. 161-164 y 166-169, respectivamente).

21 Lafone (1877; en Furlong, 1965) indica que el viaje con mulas cargadas hacia el ingenio de Pilciao tomaba tres días.

22 Rojas (2013) estima que se consumían en el ingenio de Pilciao unas 9390 toneladas al ańo de forestales (principalmente algarrobo). González (2014) calcula que se consumían 42 toneladas por día, resultando una cifra anual bastante más elevada (15330 toneladas). Más allá de estos números (que en cualquier caso son altísimos) cabe destacar que estaban relacionados con la tecnología de fundición elegida: los hornos de reverbero. Dicha tecnología, desarrollada en Europa central, no se usó en el continente americano sino hasta los inicios de la colonización (Sánchez Gómez, 1989). Según González (2014), a principios del siglo XVIII, los hornos de reverbero ganaron popularidad en Inglaterra (al punto de que en algunos lugares europeos se los conoce como "hornos ingleses"), siendo probable que los hayan introducido en Capillitas los trabajadores ingleses que se dedicaron a la explotación de los minerales en la zona desde la primera mitad del siglo XIX. 
cartloads of woods a day, a demand which not even the cyclopic trunks in the neighbourhood can long sustain. The property is backed up by large potreros, all of which are well stockated, but not a blade of grass is to be seen anywhere, all sand, sand, sand (White, 1881, p. 206).

Como se desprende de la cita, al ingresar a Pilciao a través de unas puertas gigantes, se destacaban los nueve hornos de reverbero y, tal como se observa en el plano del ingenio realizado por el inspector Ignacio Rickard (Figura 2), otras construcciones como pisones, trapiches y pozos, etcétera, asociadas al procesamiento del mineral, ${ }^{23}$ pero también otro conjunto de edificios que hacían a la cotidianeidad del ingenio no solo en términos productivos, sino también con relación a su "vida social" (carnicería, panadería, tienda, carpintería, herrería, una escuela y una iglesia). Por las cartas de Heller ya mencionadas, sabemos que en la carpintería construían carretas u otro tipo de objetos asociados al trabajo en la mina, aunque también estaba destinada a la fabricación de muebles varios para la casa principal o el laboratorio que se había instalado en el ingenio. En la herrería no solo se elaboraban las piezas de hierro para las carretas, sino incluso para los distintos instrumentos de trabajo o los moldes necesarios para la fábrica de ladrillos con que también contaba la empresa. Esta misma fuente da cuenta de que había talleres textiles (principalmente prendas de vicuńa y de lana) y que, tal como menciona White, en los alrededores la empresa poseía varios potreros que se utilizaban para invernar animales de carga indispensables para el transporte del mineral o de la leña o, inclusive, para carnearlos (principalmente bueyes).

Unas líneas aparte merecen la iglesia y la escuela. Según White la iglesia estaba en construcción al momento de su visita. Expedientes del Archivo del Obispado de Catamarca confirman que recién en 1882 se le dio licencia oficial a la capilla erigida por Lafone y, en efecto, en el plano de Rickard de 1869 no se registra ese edificio. Según la caracterización hecha por un sobrino de Lafone (Cecilio Blamey Lafone) que vivió varios años en el ingenio, se trataría de un edificio importante con capacidad para albergar a 3000 personas, una torre, artesonado de estilo inglés y vitraux, un altar mayor imponente y varias estatuas en su interior (en Furlong, 1964, p. 16). El documento por el cual Lafone pidió a las autoridades eclesiásticas que se le concediera licencia para la capilla da cuenta de un edificio mucho más modesto que el descripto por su sobrino: "quiera conceder la licencia para habilitar como capilla pública la pieza espaciosa y decente que se había levantado para servir de oratorio particular". ${ }^{24}$ De cualquier modo, más allá de sus dimensiones u opulencia, este edificio junto a la escuela conformaban un conjunto de importancia. Como se señalara en un obituario publicado en 1943 dedicado a la memoria de Lafone: "En un lugar prominente, la capilla y la escuela... tenían un papel destacado en la vida colectiva de esta apartada sociedad". 25

Así, al lado de la iglesia se levantaba la escuela, un edificio que -según Furlong (1964) - era de adobe y amplias aulas. El inventario de los bienes de la familia Lafone nos da una idea de sus dimensiones (al menos en sus últimos momentos). Con el título "Grupo piezas escuela" se describía "una pieza escuela con frente al Sud, apoyada a la capilla 8.35 x 7.50 x 3.70" y

23 Según Lafone Quevedo (1877, en Furlong 1964, p. 50) los hornos eran seis de fundición, dos de refino y uno de calcinación. El ingeniero en minas Ignacio Rickard (1869) agrega que había también, entre otras cosas, cuatro trapiches (chilian mills) y cinco pisones (stamp heads).

24 AOC, Andalgalá, Expte. "Erección de una iglesia en la Mina Restauradora en Andalgalá, 1865 y Erección de otra capilla en San Manuel en Capillitas 1882".

25 Se trata de una nota aparecida en 1943 en el Boletin de la Sociedad Argentina de Antropología (No 5-6) que, aunque no lleva firma, fue asignada por Furlong al arqueólogo Fernando Márquez Miranda, quien en ese entonces se desempeñaba como director de la publicación. Ver Márquez Miranda (1943). 


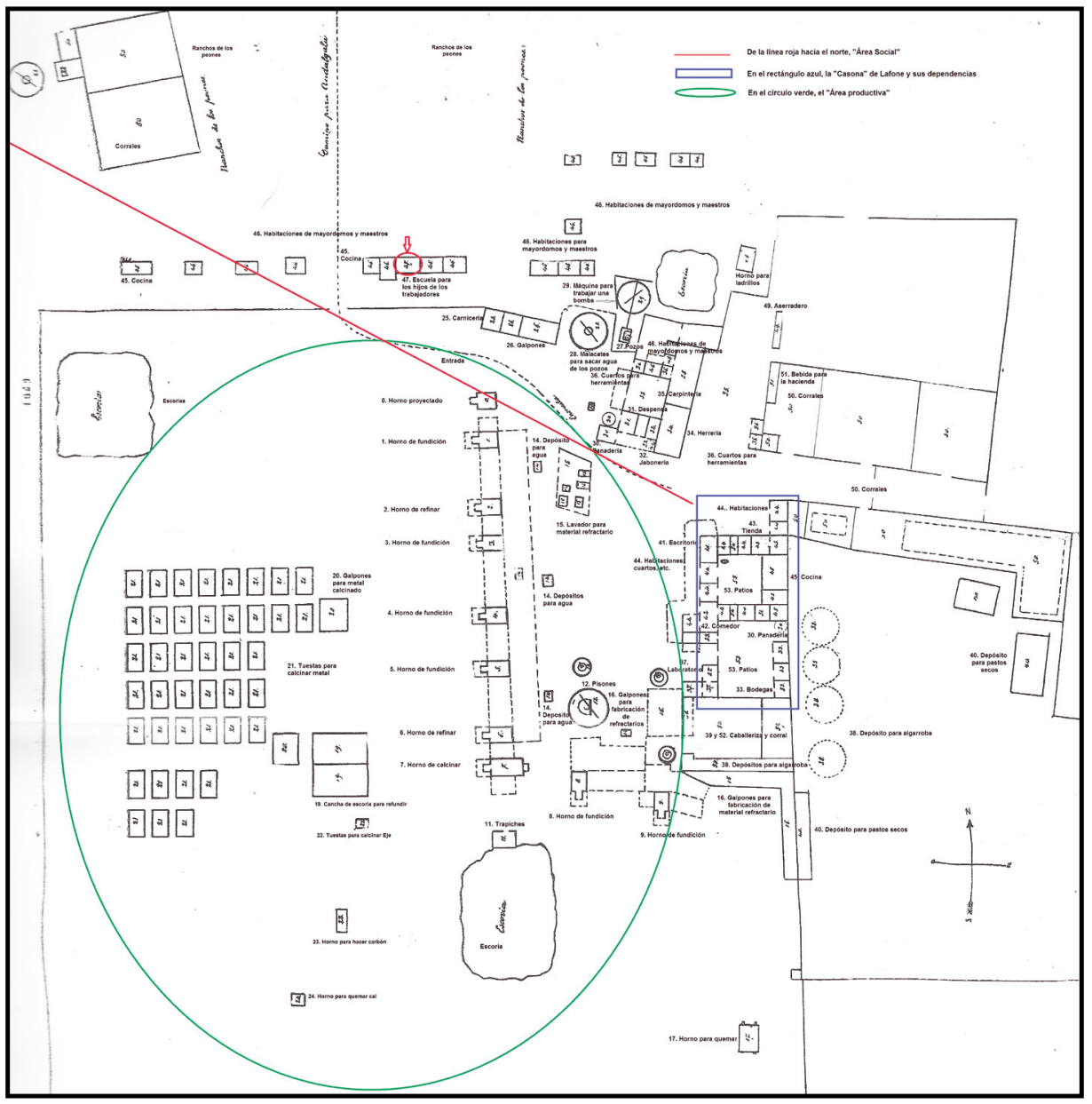

Figura 2. Plano del ingenio Pilciao.

Referencias en el original: 0 . Horno proyectado, 1, 3, 4, 5, 8 y 9. Hornos de fundición, 2 y 6 . Hornos de refinar, 7. Hornos de calcinar, 10, 11 y 13. Trapiches, 12.Pisones, 14. Depósitos para agua, 15. Lavador para material refractario, 16. Galpones para fabricación de material refractario, 17. Horno para quemar, 18. Galpón para Eje calcinado, 19. Cancha de escoria para refundir, 20. Galpones para metal calcinado, 21. Tuestas para calcinar metal, 22. Tuestas para calcinar Eje, 23. Horno para hacer carbón, 24. Horno para quemar cal, 25. Carnicería, 26. Galpones, 27. Pozos, 28. Malacates para sacar agua de los pozos, 29. Máquina para trabajar una bomba, 30. Panadería, 31. Despensa, 32. Jabonería, 33. Bodegas, 34.Herrería, 35. Carpintería, 36. Cuartos para herramientas, 37. Laboratorio, 38. Depósito para algarroba, 41. Escritorio, 42. Comedor, 43. Tienda, 44. Habitaciones, cuartos, etc., etc., 45. Cocina, 46. Habitaciones de mayordomos y maestros, 47. Escuela para los hijos de los trabajadores, 40. Depósito para pastos secos, 39 y 52 . Caballeriza y corral, 48. Horno para ladrillos, 49. Aserradero, 50. Corrales, 51. Bebidas para la hacienda, 53. Patios, 54. Pasadizos.

Fuente: Rickard (1869, anexo 13).

otras "dos piezas adosadas de 3.50 x 6.50 × 4.20 y de 4.30 x 12.60 × 4.20 ", ${ }^{26}$ todas con piso de ladrillo. Sobre el tema, al igual que para la escuela del mineral, sabemos -tal como vemos en el plano de Rickard- que al menos desde 1869 funcionaba en el ingenio y que en 1873 asistían 111 niños. Se trataba de una escuela nacional (la número 27) que al momento del Informe escolar se encontraba "en un brillante estado con la protección que le prestan los empresarios

26 AHC, Sucesorios, Caja 129, año 1901. Lafone Fisher, Samuel y Quevedo, María, fs. 20 r. 
en minas D. Samuel Lafone i su Administrador, todo con la mayor jenerosidad i desinterés" (García Aguilera, 1873, p. 191).

Respecto a las viviendas de los trabajadores en el ingenio, al igual que en otros diseños industriales, se encontraban separadas del área productiva, y las fuentes relevadas hasta el momento nos muestran que existían algunas diferencias entre ellas. Por ejemplo, en el plano dibujado por Rickard (1869) se hace una diferenciación entre ranchos y habitaciones. Por un lado, en el sector ubicado más al norte anotó (aunque no los dibujó) que allí se encontraban los "ranchos de los peones". Un poco más al sur registró una serie de edificaciones cuadradas o rectangulares que estaban alineadas al perímetro del ingenio (justo antes del ingreso al mismo), que rotuló como "habitaciones de mayordomos y maestros". Más allá de las características formales que hayan tenido ambos tipos de construcciones, es significativo el hecho de que fueran nominadas y representadas de manera diferenciada. Según Delfino (2015) en su análisis sobre las viviendas en la puna catamarqueña, la definición de "rancho" (y también la de "choza", como vimos en una cita previa del propio Lafone) ha sido históricamente estigmatizante, signo de "atraso" (asociado incluso a una pertenencia étnica indígena) y foco, a la vez, de acciones modernizadoras en determinados momentos. Para el caso de Pilciao no sabemos si a lo largo de los ańos hubo por parte de la empresa gestiones para transformar / "modernizar" esos ranchos. ${ }^{27}$ Sí creemos que la ubicación por fuera de los límites del ingenio que se observa en el plano de Rickard, en contraste con los edificios denominados "habitaciones" destinados a albergar a mayordomos y maestros, y el mantenimiento de la categorización de "ranchos" pudieron haber funcionado como elementos que espacializaban y marcaban jerarquías en Pilciao (Figura 3).

Una estructura que sin duda se diferenciaba del resto de las viviendas era la "casona" de Lafone (Figura 4). En principio, porque se encontraba dentro del perímetro del ingenio y muy cerca de una parte del área que demarcamos como "social" (pañería, carpintería, jabonería, despensa), pero fundamentalmente muy próxima al área productiva, tan cerca que en una de las cartas que Heller le escribió a Lafone mencionó que, como consecuencia del nuevo horno de ladrillos, "el umbral de la ventana de su cuarto [de Lafone], se llena [de cenizas] en cada quema" ${ }^{28}$ Por otro lado, se diferenciaba por las características que poseía. Paul Groussac, un escritor, profesor e inspector de enseñanza de origen francés que se radicó en Argentina desde muy joven, visitó en 1875 el ingenio dejándonos una concisa descripción de la "casona":

No temáis que os describa la fundición de cobre, ni siquiera la espaciosa habitación -mitad estancia, mitad home inglés- con su patio lleno de plantas, buena mesa, su biblioteca y sala de música, donde, a la noche, mientras yo, en mi

27 En el inventario de bienes de 1901, ya citado, la distinción entre "ranchos" y "piezas"/"habitaciones" sigue presente. La consulta de los censos nacionales no nos brinda demasiados datos para reflexionar al respecto. Sabemos únicamente que en 1869 se registró en Pilciao (distrito $7^{\circ}$, urbano) solo una casa con azotea que, como veremos, entendemos corresponde a la "casona" de Lafone. El resto de las viviendas (126) eran todas de techo de paja. Archivo General de la Nación (AGN), Primer Censo Nacional Argentino, Año 1869, Catamarca, Andalgalá. Tomos 138 y 139. Disponible en: https://www.familysearch. org/search/film/004306905?i=526\&cc=1462401\&cat=118747. El Censo de 1895, cuya tipificación es diferente a la del censo anterior, y por ende dificulta las comparaciones, registró -según la categorización predefinida en la cédula censal- 33 casas de "paja, zinc, madera, etc." ( 9 desocupadas y 24 ocupadas). El censista agregó a mano algunas otras categorías como "adobe" (14 casas), "piedras" (2 casas) y "postes" (9 casas). AGN, Segundo Censo Nacional Argentino, Año 1895, Catamarca, Andalgalá. Disponible en: https://www.familysearch.org/ark:/61903/3:1:S3HY-DTLL-1G?wc=M68G-RNG\%3A23936801\%2C $24019801 \% 2 \mathrm{C} 24057301 \& \mathrm{cc}=1410078$

28 AHT, Cartas del Libro Copiador, 18 de diciembre de 1869, fs. 378-383. 


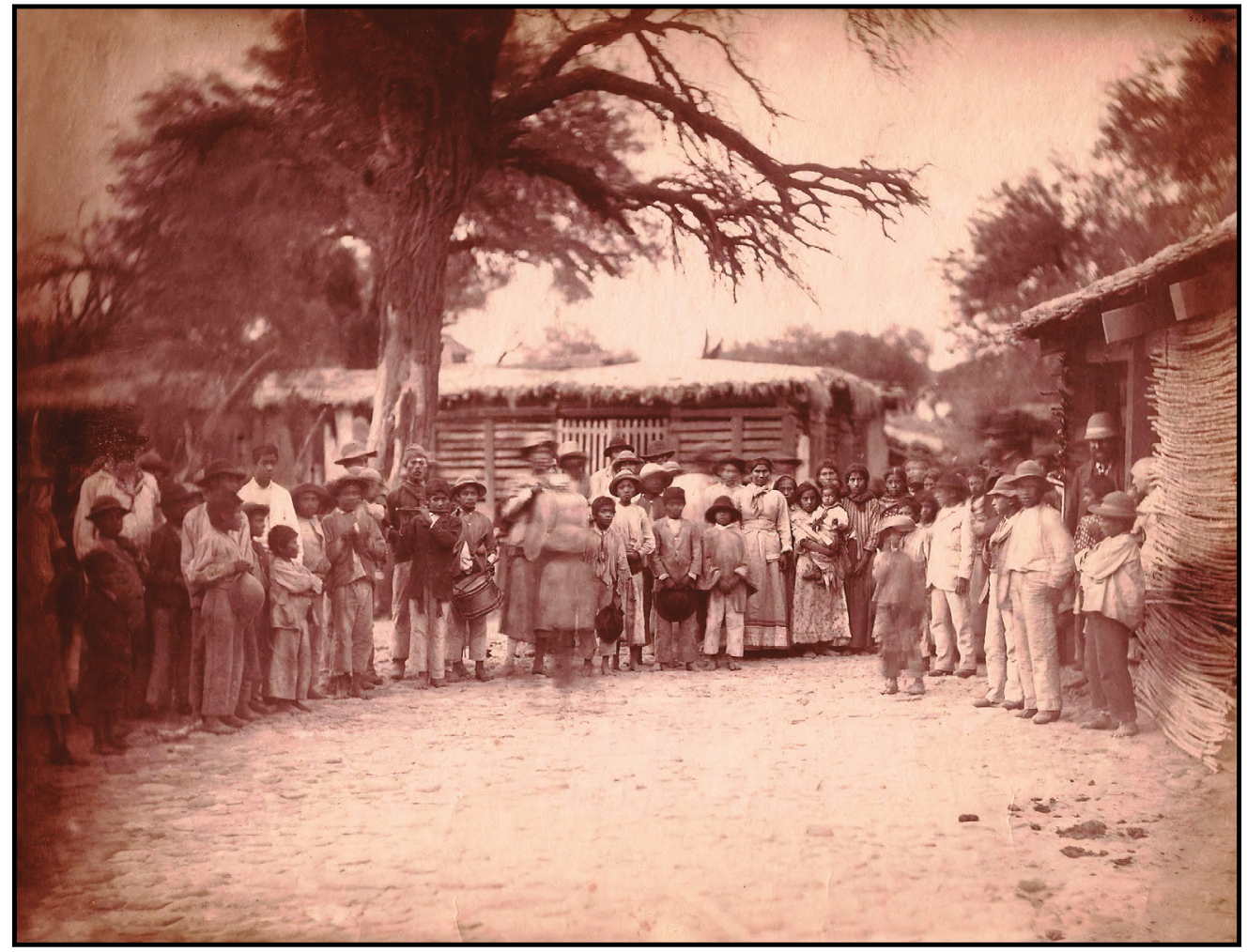

Figura 3. Población del ingenio de Pilciao.

Nota. En el Archivo Municipal de Andalgalá esta foto se exhibe con un epígrafe que dice "Familias de trabajadores de Pilciao, 1860". Creemos, sin embargo, que la fecha sería posterior; incluso de la última etapa de funcionamiento del ingenio. Foto: Gentileza de Alberto Soto.

rocking-chair, recorría una revista, mis huéspedes, pianistas ambos, tocaban, a dos o cuatro manos, algunos andantes de Bach o Beethoven. En esa casa amiga, isleta de perfecta civilización entre las más árida rustiquez, pasé una semana agradabilísima (Groussac, 1920, p. 10).

La "isleta de perfecta civilización” constituía un conjunto de amplias habitaciones y salones de paredes de adobe, ${ }^{29}$ dispuestas hacia y conectadas a través de dos patios internos (ver Figura 2). Algunas de las habitaciones funcionaban como oficinas y otras alojaban al dueño o los empleados administrativos y jerárquicos así como a varios invitados que constantemente visitaban el lugar (políticos, intelectuales, viajeros, etc.), a quienes se recibía con toda "suntuosidad" ${ }^{30}$ En el inventario de bienes de Pilciao se describe el espacio destinado a recibir a los huéspedes como "hotel"31 y por las cartas de Heller sabemos aproximadamente la fecha en que se construyó (ca. 1865-1866). ${ }^{32}$ La "casona" contaba también, tal como se desprende de la cita de Groussac, con

29 Creemos, como señalamos, que la única casa de azotea que se registró en el Censo de 1869 corresponde a esta "casona".

30 Resulta representativa la descripción que hace Ross Johnson de la estancia que allí tuvo, especialmente de la cena "suntuosa" para 50 invitados a la que asistió, así como las danzas y la música que vio y escuchó esa noche en el salón de baile (1868, pp. 141-146).

31 AHC, Sucesorios, Caja 129, año 1901. Lafone Fisher, Samuel y Quevedo, María, f. 18 v.

32 "Está hecho el cuarto en el fondo para la nueva despensa, también el cuarto al lado de la tienda para los 


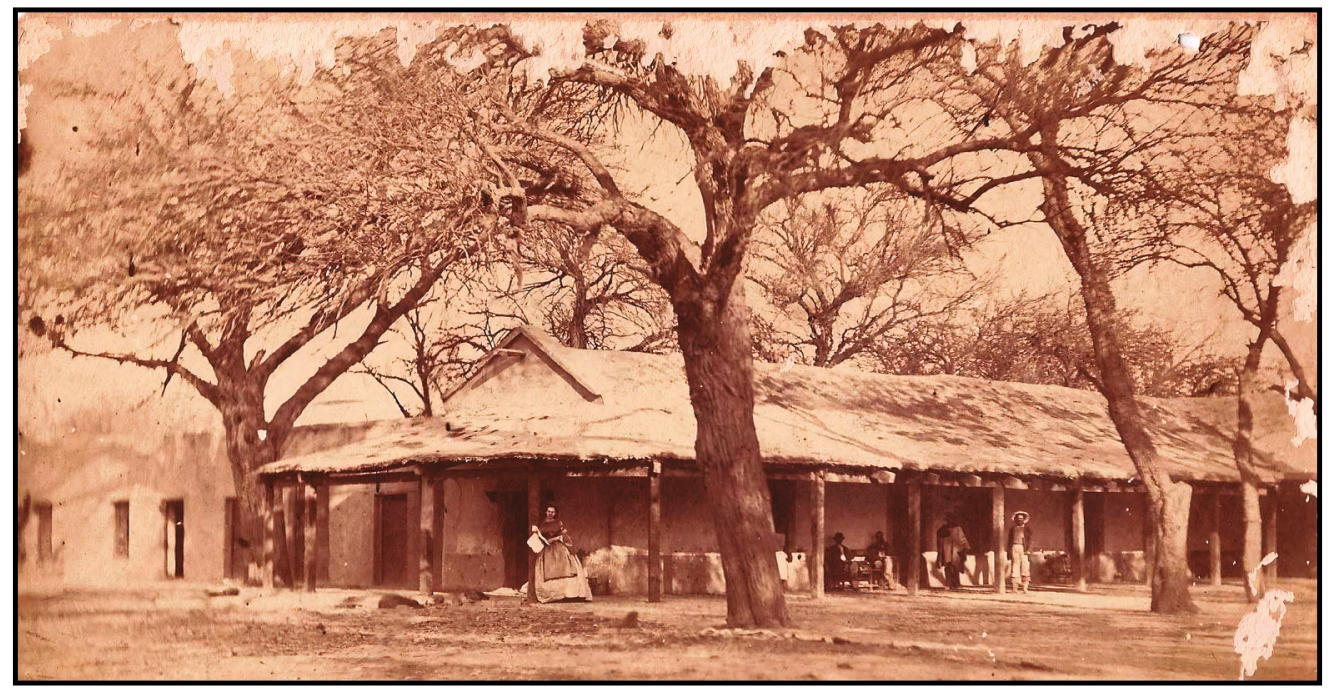

Figura 4. La casona de Lafone, ca. 1875.

Nota. La fecha de la foto es aproximada. Una litografía publicada en la obra de Espeche (1875, p. 117) reproduce prácticamente la misma imagen, por lo que tomamos esa fecha como estimación.

Foto: Gentileza de Alberto Soto.

espacios destinados a la lectura o al ocio, ${ }^{33}$ y se distinguía por el amoblamiento y los objetos que tenía. ${ }^{34}$

Es importante destacar que, desde esa "isleta", Lafone y los empleados de más rango controlaban de cerca a los trabajadores. Al respecto, la descripción que dejara el viajero Ross Johnson es ilustrativa:

The huge, flat-roofed, deeply-verandahered, comfortable-looking house was so placed that from it could be observed all the different workshops, etc. In the verandah, eager to welcome the "patron" and his guests, stood several gentlemen, the superintendent and chemist (Germans), and several Italian, Spanish, and Argentines, all in responsible positions about the works (Ross Johnson, 1868, pp. 129-30, el énfasis es nuestro).

huéspedes y no tendrá U. que dar a su cuarto ni aún a los visitantes de mas categoría, el cuarto será bien arreglado" (Carta del Libro Copiador, Pilciao, 18 de octubre de 1866, fs. 111 a 113).

33 Varios autores describen la notable biblioteca que existía en Pilciao, entre otros, con estantes especiales dedicados a la música, obras de teatro, novelas, cuentos (Cabrera, 1943), con libros de filología moderna o de antiguos cronistas (Boman, 1922) o bien revistas y diarios de actualidad como por ejemplo la Fortnightly Review que Paul Groussac menciona haber leído durante su estancia en Pilciao.

34 Algunos fragmentos de las cartas de Heller son ilustrativos en tal sentido: "El cuarto al lado de la sala está concluido y la sala también con pico, estufa, etc. y como U. no ha mandado el papel desde Córdoba, estoy casi con la intención de blanquearla, que es más conveniente para estos lugares, sobre lo que U. se convencerá también con el papel en el Fuerte; que sale muy caro cuando hay que mudarlo cada año ó dos. Después cuando U. regrese (que será algún día) y si mejoramos en el negocio, socavón, etc. siempre queda tiempo para empapelar. El sofá estará dentro de poco, están haciendo los colchones en el Fuerte y por el carpintero chileno haré hacer algunos muebles" Pilciao, 22 de agosto de 1869, fs. 267 a 272. "Mañana ó pasado acabaremos con el laboratorio y en seguido voy acabar la sala. El carpintero ha hecho una mesa redonda muy linda, dos mesas de arrimo, el sofá también está concluido hace tiempo y tendremos la sala habilitada” AHT, Cartas del Libro Copiador. Pilciao, 23 de octubre de 1869, fs. 326 a 329. 
Esta cita, aunque refiere específicamente a la casona de Lafone y al lugar que ocupaba dentro del diseño del ingenio, resume de algún modo distintos aspectos vistos a lo largo de este apartado con relación a cómo la reconfiguración espacial y las materialidades fungían, entre otros, como dispositivos de disciplinamiento. En el apartado siguiente, retomando lo hasta aquí presentado, reflexionaremos acerca de cómo esos dispositivos impactaban en el cotidiano transcurrir de los trabajadores.

\section{Los trabajadores: cuerpos y tiempos disciplinados}

Hasta el momento no hemos hecho sino describir algunas configuraciones espaciales y materialidades que acontecieron con el emplazamiento y desarrollo del emprendimiento minero de la Casa Lafone. En este apartado nos interesa hacer foco en las personas que allí vivieron y trabajaron y profundizar en el modo en que esas materialidades pudieron haber funcionado como mecanismos de disciplinamiento.

Para empezar, es importante brindar algunos datos sobre los trabajadores de la empresa. Al respecto, el propio Lafone (1894) menciona que en los meses de mayor acarreo solo el ingenio de Pilciao contaba con una población de más de 600 "almas". Cifras parecidas dan otros que visitaron la zona entre 1860 y 1870. Rickard, por ejemplo, describió que en 1868 en el ingenio trabajaban 555 personas (Rickard, 1869, p. 133). Ross Johnson estimó para esa misma época que Lafone empleaba entre 500 y 600 trabajadores (Ross Johnson, 1868, p. 128). En efecto, en el Censo Nacional de 1869, en la zona urbana del ingenio (distrito $7^{\circ}$ ) se registraron 748 personas, mayormente de nacionalidad argentina y oriundos de las provincias de Catamarca y La Rioja. ${ }^{35}$ En realidad, el emprendimiento incluía no solo a quienes vivían en el ingenio, sino también a quienes estaban asentados en zonas rurales y puestos cercanos, así como a quienes trabajaban en el mineral de Capillitas. En el censo ya citado, en la zona urbana del mineral de las Capillitas (distrito $2^{\circ}$ ), se registró una población total de 364 personas pero de esa cifra no sabemos cuántos trabajaban para la Casa Lafone y cuántos para otras empresas que explotaban minerales en la zona, pues allí no se lo especifica. ${ }^{36} \mathrm{Al}$ respecto, Rickard (1869) registró que 60 personas estaban contratadas propiamente en la mina La Restauradora, entre las cuales había 52 trabajadores argentinos (1 despensero, 2 mayordomos, 12 barreteros, 36 ayudantes y 1 cocinero) y 8 trabajadores ingleses ( 5 mineros de Cornwall, 1 herrero, 1 contador, más el capitán de la mina). Al parecer esta cifra se había incrementado levemente unos años después. En tanto, Espeche, en su memoria descriptiva de Catamarca, apuntó que en 1873 el personal en la mina se componía de "ochenta obreros del país (mas o menos) incluyendo los mayordomos de cancha, labores, despensa, etc.” y 6 mineros ingleses, incluido el capitán y un herrero de dicha nacionalidad (Espeche, 1875, p. 101). A la cifra de quienes trabajaban directamente en las minas o en el ingenio habría que agregar las personas que estaban asentadas en zonas cercanas a estos sitios y vinculadas a la minería. Por ejemplo, en el distrito rural $\mathrm{n}^{\circ} 2$ denominado

35 AGN, Primer Censo Nacional Argentino, Año 1869, Catamarca, Andalgalá, Tomos 138 y 139. Disponible en https://www.familysearch.org/search/film/004306905?i=526\&cc=1462401\&cat=118747. Las cifras del siguiente censo (1895), cuando ya el emprendimiento de Lafone prácticamente se había desarticulado, descienden a 334 personas, contando el antiguo ingenio de Pilciao solo con 127 personas y el de la Constancia (perteneciente a Adolfo Carranza y en funcionamiento hasta fines de la década de 1890), con 207 personas. AGN, Segundo Censo Nacional Argentino, Año 1895, Catamarca, Andalgalá. Disponible en: https://www.familysearch.org/ark:/61903/3:1:S3HY-DTLL-1G?wc=M68G-RNG\%3 A23936801\%2C24019801\%2C24057301\&cc $=1410078$

$36 \mathrm{Al}$ igual que en el caso de Pilciao, como es lógico, el Censo de 1895 registra una disminución de la población en "Las Minas"; unas 235 personas en total. 
"Estancias y Quebradas del Mineral”, se registraron 147 personas, mientras que en el distrito rural no 1 "Pilciao, los puestos" se asentaron 63 individuos.

Como hemos mencionado, no disponemos de mayor información sobre cómo se distribuían o cómo eran las viviendas de los trabajadores en la mina La Restauradora, pero de acuerdo a los trabajos arqueológicos realizados en las cercanías (Delfino et al., 2014), es posible pensar en un diseño similar al de otros emprendimientos que, a la vez que espacializaban las distintas tareas de la actividad minera y de la vida cotidiana, jerarquizaban a sus trabajadores. En otro artículo hemos avanzado en el análisis de cómo eran tratados diferencialmente los mineros ingleses (a quienes se les pagaba mejor tanto en moneda como en las "raciones" recibidas y se los trataba con cierta deferencia) en contraposición a los trabajadores locales, sobre quienes pesaban todos los prejuicios de la época (vagos, borrachos, delincuentes) y que repercutían en su trato general (Rodríguez, 2018). De ahí que es posible especular que esa diferenciación estaría presente también en la arquitectura del lugar, disponiendo de mejores habitaciones para los empleados ingleses y/o para aquellos que cumplían funciones administrativas, tal como ya dejamos bosquejado en el apartado anterior a partir de la información ofrecida en el inventario de los bienes de la familia Lafone. Asimismo, los datos relativos al diseño planificado de la placilla, así como la presencia temprana y patrocinada por la empresa de escuela e iglesia, nos hacen pensar en un espacio minero disciplinado y, a la vez, disciplinador.

Ahora bien, el tipo de jerarquización señalada estaba, sin duda, presente en Pilciao; probablemente desde su etapa inicial pero con más certeza en los años en que el emprendimiento se va consolidando y hasta su decadencia en la década de 1890. Por una parte, como hemos visto, el emplazamiento de la casa principal casi en el centro del ingenio y especialmente cercano al espacio productivo se imponía visualmente delineando así -como ha señalado Campi (2009) para los ingenios cañeros- un verdadero "mundo de contrastes", en el que el duro trabajo y las difíciles condiciones de vida ${ }^{37}$ se contraponían a los banquetes, las fiestas, los juegos de caza que describen diversas fuentes (Figura 5).

Asimismo, la casona que albergaba a Lafone y a sus visitantes era también la administración y, por lo tanto, hacía las veces de un dispositivo de control de todos los trabajadores. Desde el marco teórico en el que nos apoyamos, sería parte de lo que Foucault ha denominado la "arquitectura de la vigilancia", en el sentido de hacer "posible que una única mirada pueda recorrer el mayor número de rostros, cuerpos, actitudes, la mayor cantidad posible de celdas" (Foucault, 2002, p. 110).

37 Tenemos pocas noticias, por ejemplo, sobre las condiciones sanitarias y de salud de los trabajadores. Heller menciona el tema en algunas de sus cartas, inclusive haciendo referencia a su propia salud: "Hace dos semanas que fui a la mina con Harleys y me enfermé seriamente [...] después he mejorado; pero ayer y hoy no me siento nada bueno. Sufro del estómago y no sé, si no me he envenenado con los humos de plomo de las calcinas (esto no me atreveré a decir a nadie para no desacreditar el ingenio), pero deseo su llegada para irme a Tucumán ó alguna otra parte, para sanar bien y a lo menos ponerme en manos de un médico. Hace bastante tiempo que no gozo de muy buena salud" (AHT, Juan Heller. Cartas del Libro Copiador, 11de diciembre de 1866, fs. 127 a 130). "El ingenio últimamente va tomando nombre de malsano, y hay algo en esta opinión; pero personas que han estado algún tiempo aquí, sufren mucho del estómago é indigestiones [...] Es cosa muy sabida que los humos metálicos son malsanos. Yo gracias a Dios, estoy muy bueno; desde que estuve enfermo a principios del año pasado" (AHT, Juan Heller. Cartas del Libro Copiador, 30 de enero de 1870, fs. 422 a 426). 


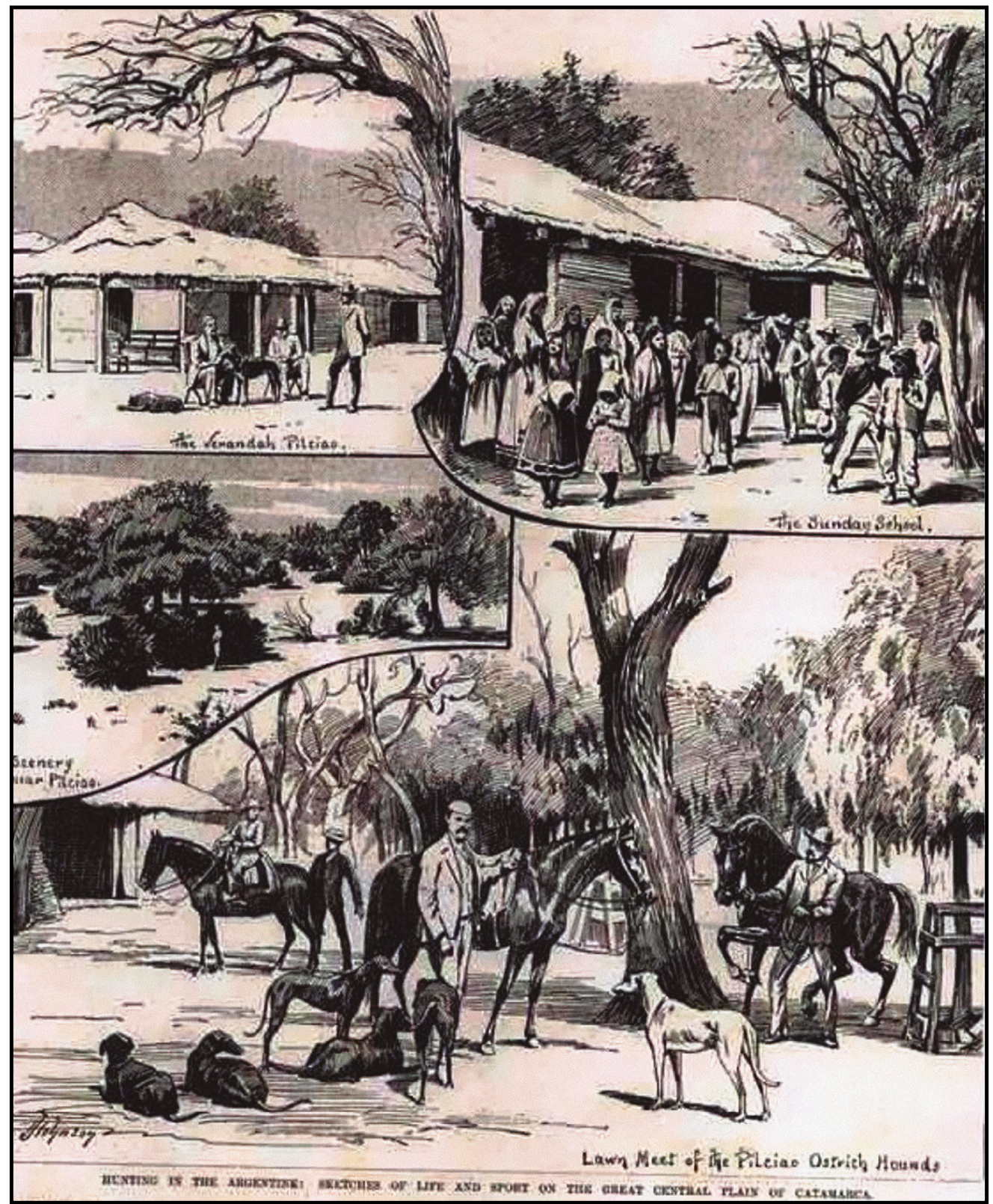

Figura 5. Representación de escenas en Pilciao, entre ellas la caza del avestruz. Fuente: The Daily Graphic, 30 de diciembre de 1891, "Hunting in the Argentine".

Por otra parte, dicha casa junto con la iglesia y la escuela se articulaban también para "ordenar" los tiempos dentro del ingenio tanto de los trabajadores como de sus familias. Como describe Márquez Miranda (1958), el trabajo en las faenas mineras se extendía de lunes a viernes, mientras que sábados y domingos eran días de descanso laboral, aunque -como veremos- destinados a una estricta rutina con la que había que cumplir. 
Es interesante observar que más allá de lo relativo al trabajo, que seguramente tenía sus jerarquías por oficios o tipos de faenas ${ }^{38}$ con sus correspondientes cadencias, los tiempos de descanso y de ocio también eran regulados por la empresa en esa experiencia abarcante que, en palabras de Sierra Álvarez (1990), buscaba modelar un “obrero soñado”. Según relata el padre Cabrera (1943), quien viviera de niño en el ingenio, uno de los hitos que marcaba el ritmo del "fin de semana" eran las denominadas "Conferencias". Se realizaban puntualmente todos los domingos a las diez de la mañana y consistían en reuniones a las que debía concurrir toda la población al son de las campanas y en las que varios niños del ingenio (que se preparaban durante la semana en la escuela), vestidos para la ocasión, ${ }^{39}$ recitaban cuentos, cantaban en el coro que el mismo Lafone dirigía y cuyo repertorio era seleccionado por él personalmente ( $\mathrm{Fi}$ gura 6). También designaba a un muchacho para que leyera una parte del Evangelio que luego él explicaba a los oyentes. La reunión finalizaba con la narración de un cuento de "Viejas, del Chiquillo o de las Mil y una Noches" por parte de Lafone y el canto nuevamente del coro (Cabrera, 1943, pp. 12-15). Cabe resaltar que dichas reuniones se hacían en la iglesia, en donde se disponía formalmente todo el espacio a tal fin y en donde cada uno de los participantes debía ocupar el lugar estrictamente asignado:

Al propio tiempo comenzaba el repiquetear de las campanas, y las gentes iban llegando con la cachaza que les era ingénita, pero deseosas de participar en aquel acto sacro y civil, religioso y profano. Uno y otro lado de lo que era el presbiterio, había unos duros sillones de algarrobo, cubiertos por tapices colorados o alfombras indígenas de variados colores. Allí tomaba asiento don Samuel y, a la par de él, sus parientes e invitados de honor, que nunca faltaban: verticalmente situados, respecto a éstos, estaban los bancos de la multitud, los que se llenaban totalmente. Allí estaban los obreros, y con ellos sus esposas e hijos. Frente a ellos, y entre las dos filas de asientos de honor había una tarima de igual amplitud, que se elevaba como un metro sobre el nivel del piso. Desde allí leía el lector el Evangelio, desde allí explicaba don Samuel lo leído y desde allí se declamaba o recitaba (Furlong, 1964, pp. 18-19).

Luego de la Conferencia (cerca de la una de la tarde) se daba paso al almuerzo, a una breve siesta, y se desarrollaban a continuación distintos juegos en los que participaba todo el pueblo (taba, bochas, juegos de mesa, fútbol, cricket, etc.). Al atardecer, volvían a sonar las campanas para que la gente se reuniera de nuevo en la iglesia, en donde Lafone dirigía el rezo del Rosario (Márquez Miranda, 1958).

38 Rickard (1869), por ejemplo, establece que en el ingenio los trabajos se dividían del siguiente modo: "empleados superiores": 2 (extranjeros), de "escritorio": 2 (uno extranjero y uno argentino), "mayordomos": 5, "herreros": 4, “carpinteros": 12, "fundidores maestros": 2, "fundidores ayudantes": 8, "fundidores peones": 40, “albañiles": 4, “peones": 76, “arrieros": 270, "burreros": 70, “carretoneros": 20, "hachadores de leña": 40; todos estos de nacionalidad argentina y sumando un total de 552 personas.

39 Cabrera dice: "A todos estos gastos se agregaba el traje con que nos obsequiaba todos los ańos, el que debíamos usarlo tan solo los domingos y días de fiesta. Era un traje uniforme, de pantalón blanco y chaqueta azul, de género de muy buena clase y que él adquiría por piezas 'para mis niños' como decía al efectuar la compra (Cabrera, 1943, p. 20). 


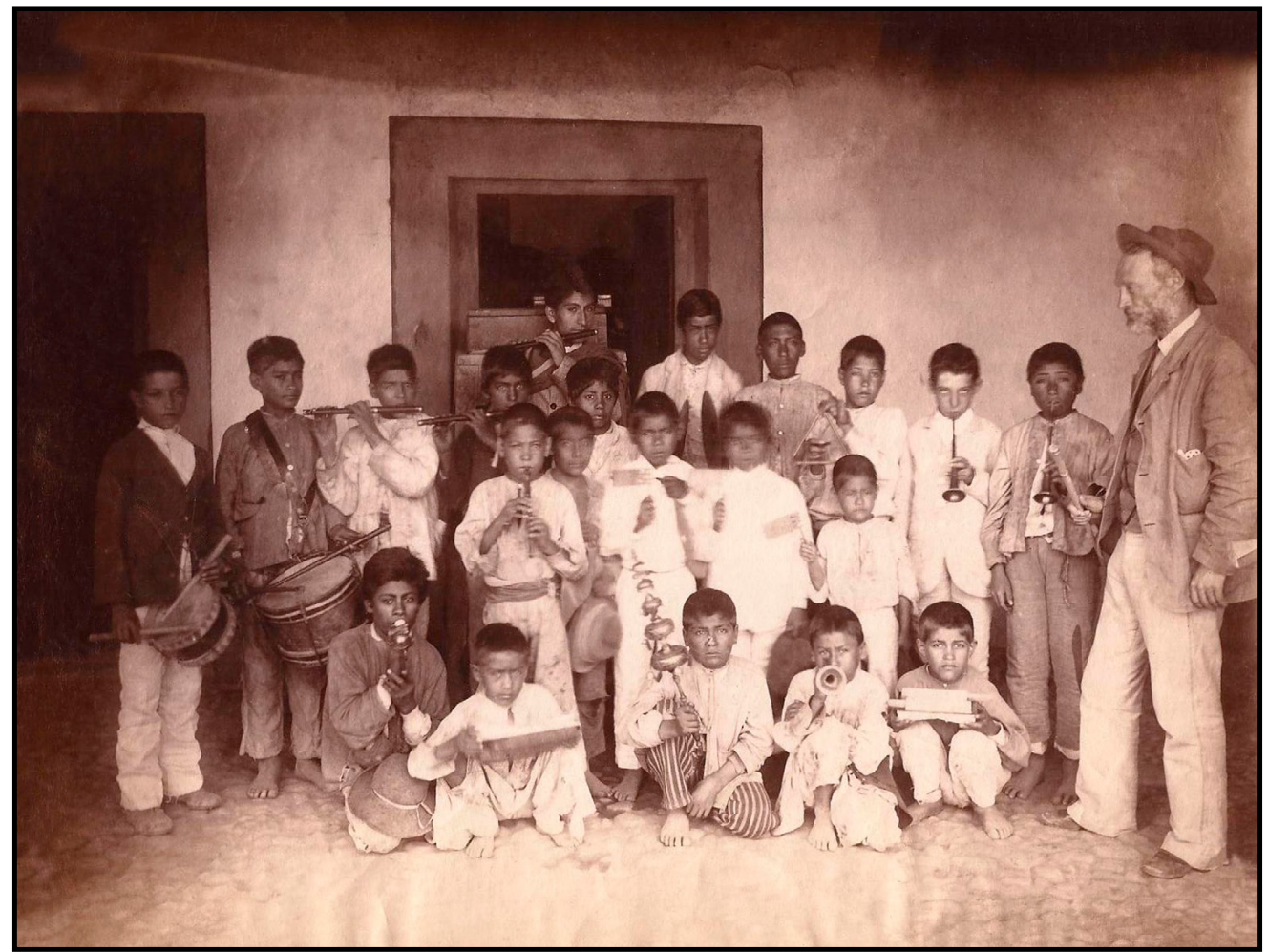

Figura 6. Coro de niños del ingenio. A la derecha, Samuel Lafone Quevedo.

Nota. Tampoco tenemos fecha precisa para esta foto, pero seguramente fue tomada después de 1872, año a partir del cual Lafone se instaló definitivamente en el ingenio. Foto: Gentileza de Alberto Soto.

El trabajo y el ocio, pautados temporal y espacialmente, respondían a la lógica de disciplinamiento de la mano de obra que exigía el complejo industrial minero y que se acompañaba de otras prácticas; algunas más evidentes como los castigos corporales ${ }^{40}$ y otras -como estas aquí referidas- más sutiles y que Lafone se empeñaba en desplegar en su trato cotidiano. El padre Cabrera afirma en su libro que toda "oportunidad que se presentaba, era aprovechada por don Samuel para impartir útiles enseñanzas" (Cabrera, 1943, p. 26) y describe distintas escenas de su niñez en las que constantemente "nuestro viejito" realizaba minúsculas acciones disciplinarias. En particular, del material relevado hasta el momento (y aunque resta aún estudio específico al respecto), podemos inferir el lugar destacado que tenía la niñez para el proyecto de Lafone. De ahí la importancia que él le daba a la institución escolar (tanto en la mina como en el ingenio), a donde no solo había invertido dinero para costear las instalaciones, los sueldos de los docentes o impartiendo clases sino, inclusive, ocupando cargos en el área educativa del departamento. ${ }^{41}$ El remate de una de las anécdotas relatadas por el padre Cabrera de cuando era niño, en la que había desobedecido una orden del "viejito", puede ilustrar este punto "-Mira, Pedro, [le dijo Lafone al niño Cabrera] no es que me haga falta esta botella; lo que quiero, es que aprendas a obedecer (Cabrera, 1943, p. 26, el énfasis es nuestro)”.

40 “Tenemos al rengo Vallejos y dos mujeres en el cepo por haber traído aguardiente anoche [...] Hoy he botado al rengo, la mujer que tiene y otro peón más por contrabandistas; han estado ayer y toda la noche en el cepo" AHT, Juan Heller. Cartas del Libro Copiador, 12/12/1869, fs. 372 a 375.

41 Entre 1878 y 1892 se desempeñó como inspector de escuelas de enseñanza primaria del departamento de Andalgalá (Furlong, 1964). 
Podríamos enmarcar entonces las relaciones entabladas por Lafone con los trabajadores dentro de lo que se ha denominado "paternalismo industrial", definido como:

[...] un conjunto de mecanismos de control destinados a cubrir una serie de demandas sociales de los trabajadores, a saber, vivienda, salud, educación de los infantes, entretención y algunos aspectos de la sociabilidad, utilizados por las empresas para adaptar a sus operarios a las demandas al interior de las villas o poblados diseñados para su permanencia en las cercanías de las labores fabriles o extractivas, asegurando de esta forma la existencia de mano de obra segura y altamente adiestrada (Godoy Orellana, 2015b, pp. 118-19).

Es decir, el vínculo personal (no regido por una estricta lógica del mercado y semejante al de un padre de una "gran familia industrial" 42 ) que con el tiempo parece haber desarrollado Lafone para con los trabajadores pudo estar asociado a la voluntad de modelarlos bajo los preceptos productivos de la empresa. Una cita del administrador Heller refiriéndose a las características de los trabajadores y a cómo debían ser tratados, puede resultar ilustrativa:

[...] hay que enseñar a la gente como deben y pueden trabajar y hasta hacerles gastar y crearles necesidades; pues cuando no las tienen, como son flojos, no trabajan. Por ejemplo: la mayor parte de nuestros peones son de Belén y cuando hay allí regular cosecha de maíz no trabaja la gente; sabiendo esto; compro allí todo el maíz que puedo hasta que se pone escaso y caro, con esta medida luego vienen al ingenio para trabajar, comen el maíz y ganan plata. ${ }^{43}$

O sea, que no era solo imponerles una nueva rutina de trabajo adecuada al ritmo industrial, sino también una nueva forma de vida de acuerdo a los valores morales de estos empresarios. Como señala Venegas Valdebenito (2014), el paternalismo antes señalado se complementa con el disciplinamiento en tanto desde esa asociación es posible controlar a las personas en diferentes dimensiones (vigilancia en los espacios y tiempos de trabajo, así como también en los extra laborales; es decir, en los ámbitos propios de la sociabilidad, el ocio y las celebraciones). Por ejemplo, una constante a lo largo de las cartas que escribe Heller es la referencia al carnaval y a los efectos nocivos que traía para el trabajo. La siguiente frase es elocuente en dicho sentido: "Mala época para recibir visitas; pero estoy ya preparado de antemano; lo peor es por cocinero y sirvientes que todavía andarán con el carnaval en la cabeza [...]. En cuanto a trabajo por supuesto nada; tambor vidalita es lo que hay". ${ }^{44}$ Sin duda, estas celebraciones como el carnaval (entre otras, asociadas a las "chupanzas" ${ }^{45}$ ) eran vigiladas para ser erradicadas o al menos "domesticadas" dentro del ámbito diseñado por la empresa con el objeto de mejorar la productividad. Probablemente también -como destaca Godoy Orellana (2009)- con el propósito de evitar disturbios, protestas o levantamientos propiciados por la aglomeración de una

42 Al respecto véase el trabajo de Lupano (2009).

43 AHT, Juan Heller. Cartas del Libro Copiador, 19 de febrero de 1870, fs. 442 a 447.

44 AHT, Juan Heller. Cartas del Libro Copiador, 27 de febrero de 1870, fs. 452 a 455. El destacado es nuestro.

45 Cabe destacar que el carnaval coincide con el verano y, por ende, con el “tiempo de la algarroba”. De ahí algunas de las quejas de Heller respecto a la aloja (bebida alcohólica preparada con las vainas fermentadas del algarrobo y, además, de alto valor simbólico en la zona): "Anoche ha habido una borrachera tremenda con aloja de algarroba nueva; pero todo se acabó bien”. AHT, Juan Heller. Cartas del Libro Copiador, 15 de enero de 1870, fs. 408 a 411. 
multitud dispuesta a transgredir el orden e impedir el "progreso" para el que los empresarios creían haber estado destinados. Según reflexión de Sierra Álvarez (1990), la producción del "obrero modelo" respondía a una obra de civilización, moralización y redención humanas que debía ser ejecutada -como deber social de los patrones- y que, en definitiva, funcionaba como legitimación social del programa paternalista.

\section{Conclusiones}

Los datos aquí expuestos han apuntado a mostrar que durante la segunda mitad del siglo XIX el paisaje tanto de Capillitas como del algarrobal de Pilciao fue profundamente modificado a través de la infraestructura propia de un emprendimiento minero, así como de la instalación de edificios/instituciones "civilizatorias" (como la escuela y la iglesia) y una organización espacial que implicó, además, una determinada disposición del tiempo. Los trabajadores en general, pero especialmente los de ámbitos rurales cercanos que poco a poco llegaron a trabajar a este complejo minero, a veces de manera voluntaria y otras de manera forzada, tuvieron que adaptarse a nuevos ritmos de trabajo, labores y formas de vida. El disciplinamiento de esos cuerpos (su "docilización", en términos foucaultianos) se produjo de diversas maneras, siendo la reconfiguración espacial y arquitectónica una de ellas. Así los trabajadores, nucleados o vinculados a un espacio tendiente a la urbanización, transcurrieron cotidianamente en un ámbito en el que, de maneras sutiles pero constantes, se marcaban jerarquías, se restringía o habilitaba la circulación por los distintos espacios y, como consecuencia de ello, se pautaban los tiempos no solo del trabajo sino también del "ocio" y del "descanso". El área de la empresa era, en palabras de Sierra Álvarez (1990), un "mundo completo" en el que se reunían los espacios de trabajo y de vida pero de manera zonificada. En ese mundo convivía el conjunto de grupos sociales (patrones, capataces, curas, maestros, obreros), pero espacialmente separados y jerárquicamente dispuestos; este ordenamiento debía tener un efecto moralizante.

Cuánto de particular tuvo este emprendimiento minero con relación a otros que se desarrollaron en paralelo por la zona, es difícil determinarlo por el momento, en tanto aún no hemos avanzado en el análisis comparativo. En muchas de las fuentes analizadas, es el propio Lafone el que insiste en diferenciar su proyecto presentándolo como verdaderamente inglés. Distingue, como en la cita que encabeza este artículo, la infraestructura y las tecnologías utilizadas (piques y galerías, tranvías, bombas, etc.) y el diseño del emplazamiento urbano cercano a la mina (al que quizás podríamos agregar el del ingenio). ${ }^{46}$ Probablemente, la insistencia de Lafone en distinguir su emprendimiento buscara ubicarlo como de mayor jerarquía y civilidad que otros desarrollos mineros cercanos. Al respecto, la tensión/competencia entre Lafone y Carranza se vislumbra en la cita ya referida, pero puede rastrearse también en las cartas que escribe Juan Heller. En ellas emerge este conflicto puntual así como las ideas y los prejuicios que tanto el administrador como el propio Lafone tenían respecto a la población local (no solamente sobre los peones, sino también sobre las élites). ${ }^{47}$

46 También varios de los viajeros que visitaron el lugar hicieron comparaciones con ciudades inglesas o europeas. Como hemos visto, Ernest White (1880) comparaba el ingenio de Pilciao con una "Saltaire en miniatura" (villa industrial inglesa fundada en 1853) y Ross Johnson, al ver Pilciao, creía haberse transportado al "black country" o a Birmingham o Liège (1868, p. 129).

47 En las cartas de Heller para dar cuenta del contexto político o caracterizar diferentes situaciones aparecen expresiones como "país salvaje", "infierno", "desgraciada provincia”. Un foco concreto de crítica es la religión católica a la que especialmente Heller considera causa de los "atrasos del pueblo". No está de más recordar que tanto el administrador como Lafone eran de familias protestantes, aunque este último se convertirá posteriormente en un devoto católico (para más detalles ver Rodríguez, 2018). 
Más allá de las posibles diferencias entre el emprendimiento de Lafone y otros de la zona y de su carácter más o menos inglés, lo que nos muestra el caso aquí analizado es que allí se ensayaron tempranamente (casi como un laboratorio) una serie de prácticas de disciplinamiento industrial (que luego veremos en otros espacios como los ingenios azucareros tucumanos) ${ }^{48} \mathrm{y}$ que implicaron impactos en el paisaje, los recursos naturales y principalmente sobre la vida de quienes allí habitaron y trabajaron. Por supuesto, la voluntad de disciplinar constantemente a esa masa de personas, de diferentes modos y a través de diversos dispositivos, se vincula a lo que el dueño y los administradores del emprendimiento consideraban indisciplinas laborales, pero también morales. Estas acciones indisciplinadas que aparecen en las fuentes pueden leerse como pequeñas o grandes resistencias y, por ende, como desafíos al poder. Aunque estos aspectos son más opacos y esquivos en los documentos, deben ser explorados aún. Resulta imposible caracterizar acabadamente la minería decimonónica en general, y de Catamarca en particular, sin comprender los modos en que los trabajadores vivieron estos procesos y disputaron espacios y sentidos en el ámbito del trabajo y la vida cotidiana. Explorar esas "vetas" ocultas, intentar observar modos distintos de habitar y trabajar en las minas prestando atención, por ejemplo, a "otras minerías", de pequeña escala o artesanal, o al papel que tuvieron actores sociales menos visibles en las fuentes (como mujeres y niños), ${ }^{49}$ nos permitirá ir de a poco completando y complejizando nuestras observaciones. Sobre estos temas, y en conexión con lo aquí analizado, esperamos avanzar próximamente.

48 Cabe agregar que hacia 1872 Juan Heller formaría sociedad con los hermanos Juan Manuel y Juan Crisóstomo Méndez para fundar en Tucumán el ingenio azucarero Trinidad, emprendimiento al que poco después se sumaría como socio Samuel Lafone Quevedo (Peña de Bascary, 1976).

49 La publicación de un reciente dossier, por ejemplo, apunta a poner en evidencia el rol de las mujeres en el ramo minero en diferentes períodos y regiones. En el artículo introductorio, sus coordinadoras muestran que si bien el trabajo minero se ha asociado con la masculinidad, hay sobradas evidencias, en una mirada de larga duración, de que las mujeres participaron y (participan) activamente en el mismo. Las razones de su borramiento de la historia de la minería se explica, entre otras razones, por la implementación desde las primeras décadas del siglo XIX de leyes de protección de mujeres y niños, resultando en su exclusión del trabajo dentro de las minas. Asimismo, se relaciona con la imposición de un modelo que consideraba a las mujeres principalmente como madres y reproductoras de la fuerza de trabajo (Barragán y Papastefanaki, 2020). 


\section{Referencias citadas}

Alderete, M. (2004). El distrito Capillitas. En Lavandaio, E. y Catalano, E. (Eds.). Historia de la minería argentina. Tomo 2 (pp. 47-60). Buenos Aires: SEGEMAR.

Alonso, R., Solís, N., Silva de Cruz, E., Robles, N. (2018). Historia Minera colonial. Salta: Mundo editorial.

Alvero, L. (2013). Economía y política en Catamarca durante el período 1846-1855. Ponencia presentada en XIV Jornadas Interescuelas/ Departamentos de Historia. Departamento de Historia de la Facultad de Filosofía y Letras. Mendoza, Universidad Nacional de Cuyo, Mendoza.

Barragán, R. y Papastefanaki, L. (2020). Women and Gender in the Mines: Challenging Masculinity Through History: An Introduction. International Review of Social History, 1-40. doi:10.1017/ S0020859019000774

Boman, E. (1922). Samuel Alejandro Lafone Quevedo. Journal de la Société des Américanistes, 14-15, 205213.

Bonaudo, M. (1999). A modo de prólogo. En Nueva Historia argentina. Tomo IV. dirigido por M. Bonaudo (pp. 11-26). Buenos Aires: Sudamericana.

Cabrera, P. (1943). Apuntes sobre la vida intima del sabio Samuel A. Lafone Quevedo. Buenos Aires: Escuela Gráfica del Colegio Pío IX.

Campi, D. (2009). Contrastes cotidianos. Los ingenios del norte argentino como complejos socioculturales, 1870-1930". Varia Historia, 25(41), 245-267.

Campi, D. y Richard-Jorba, R. (2004). Transformaciones productivas, espaciales y sociales en la Argentina extrapampeana. Tucumán y Mendoza entre 1850 y 1890. Boletín americanista, 54, 35-62.

Catalano, E. (2004). Antecedentes y estructura histórica de la minería argentina. En Lavandaio, E. y Catalano, E. (Eds.). Historia de la minería argentina. Tomo 1 (pp. 1-176). Buenos Aires: SEGEMAR.

Contreras, C. (1988). Mineros y Campesinos en los Andes. Mercado laboral y economía campesina en la sierra central siglo XIX. Lima: Instituto de Estudios Peruanos.

Contreras, C. (2015) El asiento minero de Morococha en la sierra central del Perú, desde el siglo XVIII hasta el presente. En Uribe Salas, J. A. y Flores Clair, E. (Coords.). Comercio y minería en la historia de América Latina. México: Universidad Michoacana San Nicolás de Hidalgo - Instituto Nacional de Antropología e Historia.

Criado Boado, F. (1999). Del terreno al espacio: planteamientos y perspectivas para la Arqueología del Paisaje. CAPA, 6, 1-77.

Delfino, D. (2015). Los vendavales de políticas estatales y el resistente lenguaje de las "casas mochas" en la puna catamarqueña. Cuadernos de la Facultad de Humanidades y Ciencias Sociales-UNJu, 47, 181-195.

Delfino, D., Dupuy, S. y Quesada, M. (2014). El ciclo del cobre en Minas Capillitas (provincia de Catamarca, Argentina) en la segunda mitad del siglo XIX: tensiones entre lógicas productivas, escalas tecnológicas y unidades sociales. Estudios Atacameños. Arqueología y Antropología Surandinas, 48, 119-140. 
De Moussy, M. (1860). Description géographique et statistique de la Confédération Argentine. Tomo II. Paris: Didot Frères.

Deustua, J. (1995). “Campesino, el patrón no comerá más de tu pobreza”. Economía, mercado y campesinos en los Andes. El caso de la minería peruana en el siglo XIX. Documento de trabajo No 70 Serie Economía. Lima: Instituto de Estudios Peruanos.

Deustua, J. (2009). El embrujo de la plata: la economía social de la minería en el Perú del siglo XIX. Lima: Instituto de Estudios Peruanos - Banco Central de Reserva del Perú.

Deustua, J. (2011). Guano, salitre, minería y petróleo en la economía peruana, 1820-1930. En Contreras, C. (Ed.). Compendio de historia económica del Perú. Tomo IV: Economía de la primera centuria independiente. Lima: Instituto de Estudios Peruanos - Banco Central de Reserva del Perú.

Espeche, F. (1875). La provincia de Catamarca. Buenos Aires: Imprenta Biedma.

Farro, M. (2013). Las lenguas indígenas argentinas como objeto de colección. Notas acerca de los estudios lingüísticos de Samuel A. Lafone Quevedo a fines del siglo XIX”. Revista de Indias, 73(258), 525-552.

Foucault, M. (2002). Vigilar y Castigar. Nacimiento de la prisión. Buenos Aires: Siglo veintiuno editores Argentina.

Furlong, G. (1964). Samuel A. Lafone Quevedo. Buenos Aires: Ediciones Culturales Argentinas.

García Aguilera, V. (1873). Anales de la educación común en la provincia de Catamarca. Tomo II, núm. 4. Catamarca: Imprenta del Colegio Nacional.

Gil Montero, R. (2014). Ciudades efimeras. El ciclo minero de la plata en Lipez (Bolivia), siglos XVI-XIX. Lima: Instituto Francés de Estudios Andinos - Plural Editores.

Godoy Orellana, M. (2009). Fiestas y revueltas entre los mineros del Norte Chico, 1840-1900. En Ortega Martínez, L., Godoy Orellana, M. y Venegas Valdebenito, H. (Eds.). Sociedad y minería en el Norte Chico, 1840-1930 (pp. 67-96). Santiago: Universidad Academia de Humanismo Cristiano y Universidad de Santiago de Chile.

Godoy Orellana, M. (2015a). Las placillas del desierto. Construcción de espacio urbano en el despoblado de Atacama. Bolivia y Chile, 1870-1900, Amérique Latine Histoire et Mémoire. Les Cahiers ALHIM [En línea], 29 | 2015, Publicado el 16.11.2015, consultado el 9.06.2017. Recuperado de http://journals.openedition.org/alhim/5183

Godoy Orellana, M. (2015b). Las casas de la empresa: paternalismo industrial y construcción de espacio urbano en Chile. Lota, 1900-1950. Universum, 30, 115-136.

González, L. (2014). Minería en Capillitas, Catamarca. Ingenios transhumantes y combustibles en el valle de Yocavil (mediados del siglo XIX). En Rodríguez Leirado, E. y Schávelzon, D. (Eds.). Actas del V Congreso Nacional de Arqueología Histórica. Buenos Aires: Centro de Arqueología Urbana, (CD ROM).

Groussac, P. (1920). El romanticismo francés. El teatro de Dumas y Musset. Revista Nosotros, 136, 9-25.

Haber, A. y Delfino, D. (1995-96). Samuel Lafone Quevedo and the construction of archaeology in Argentina. Revista de História da Arte e Arqueologia, 2, 31-43. 
Hoskold, H. (1889). Oficial memoria general y especial sobre las metalurgia, leyes de minas, recursos ventajas, etc., de la explotacion de minas en la Republica Argentina. Buenos Aires: Courrier de La Plata.

Illanes, M. A. (2003). Chile des-centrado: formación socio-cultural republicana y transición capitalista, 18101910. Santiago: LOM Ediciones.

Lafone Quevedo, S. (1888): Londres y Catamarca. Buenos Aires: Imprenta y Librería Mayo.

Lafone Quevedo, S. (2010 [1894]). Relación histórico-descriptiva del mineral de las Capillitas y de sus injenios en Andalgalá. En Caro, R. (Ed.). Escritos económicos (pp. 132-143). Catamarca: Universidad Nacional de Catamarca.

Lafone Quevedo, S. (1898). Tesoro de Catamarqueñismos. Nombres de lugar y apellidos indios, con etimologías y eslabones aislados de la lengua cacana. Buenos Aires: Imprenta de Pablo Coni e Hijos.

Lafone Quevedo, S. y F. Schickendantz (1999 [1881]). Memoria descriptiva de la provincia de Catamarca (1881). Universidad Nacional de Catamarca, San Fernando del Valle de Catamarca, Argentina.

Lupano, M. M. (2009). La Gran Familia Industrial. Espacio urbano, prácticas sociales e ideologia (1870-1945). Buenos Aires: Santiago Arcos Editor.

Mariani, A. (2009). La familia y empresas de Samuel Fisher Lafone, 1805- 1871. Actas de las 6a Jornadas de Investigación en Historia Económica. Recuperado de www.audhe.org.uy/sextas_jornadas/Samuel_Fisher_Lafone_1.doc (fecha de acceso 14.04.2012).

Márquez Miranda, F. (1943). Don Samuel en Pilciao. Boletín de la Sociedad Argentina de Antropología, 5-6, 67-69.

Márquez Miranda, F. (1958). Lafone-Quevedo, el arqueólogo educador. Trabajos y Comunicaciones, 7, 127134.

Meléndez, A. (2016). La vida en mina Dal (El Alto, Catamarca). Aproximaciones desde la arqueología. Comechingonia, 20(2), 189-214.

Ortega Martínez, L. (2005). Chile en ruta al capitalismo. Cambio, euforia y depresión 1850-1880. Santiago: DIBAM - LOM - Centro de Investigaciones Diego Barros Arana.

Ortega Martínez, L. (2009). Del auge a la crisis y la decadencia. La minería del cobre entre 1875 y 1925. En Ortega Martínez, L., Godoy Orellana, M. y Venegas Valdebenito, H. (Eds.). Sociedad y minería en el Norte Chico, 1840-1930 (pp. 17-66). Santiago: Universidad Academia de Humanismo Cristiano y Universidad de Santiago de Chile.

Osatinsky, A. (2015). Catamarca entre los siglos XIX y XXI. Del estancamiento económico al crecimiento sin desarrollo. Hic Rhodus, 7, 17-34.

Oszlak, O. (1982). Reflexiones sobre la formación del estado y la construcción de la sociedad argentina. Desarrollo Económico. Revista de Ciencias Sociales, XXI(84), 531-548.

Peña de Bascary, S. (1976). Un marino danés en la aventura de El Pilciao. La Gaceta, Tucumán, Suplemento Literario, 22 de febrero de 1976.

Peña de Bascary, S. (1978). Lafone: Gentleman, minero, arqueólogo. La Gaceta, Tucumán, Suplemento Literario, 9 de enero de 1978. 
Peña de Bascary, S. (1980). El temperamental Federico Schickendantz. La Gaceta, Tucumán, Suplemento Literario, 18 de mayo de 1980.

Peña de Bascary, S. (2014). Federico Schickendantz. Un científico investigador y vehemente. Revista de la Junta de Estudios Históricos de Tucumán, 14, 86-124.

Rickard, I. (1869). Informe sobre los distritos minerales, minas y establecimientos de la República Argentina en 1868-69. Buenos Aires: Imprenta, litografía y fundición de tipos a vapor.

Rodríguez, L. (2015). Explotaciones mineras intermitentes y promesas permanentes de riqueza. Descubrimientos, redescubrimientos y ordenamientos al sur del Valle Calchaquí, fines del siglo XVII-mediados del XIX. Población y Sociedad, 22(1), 61-91.

Rodríguez, L. (2018). El "problema" de los trabajadores en un emprendimiento minero del oeste catamarqueño (segunda mitad del siglo XIX). Aportes desde un corpus documental poco conocido. Mundo de Antes, 12(2), 97-125.

Rodríguez Ostria, G. (2001). Los mineros de Bolivia en una perspectiva histórica. Revista Convergencia, 24, 271-298.

Rojas, F. (2013). Rol de la minería y el ferrocarril en el desmonte del oeste riojano y catamarqueño (Argentina) en el período 1851-1942. Población y Sociedad, 20(1), 5-39.

Rojas, F. y Wagner, L. (2017), “Desarrollos” fallidos en la minería histórica. Famatina y Capillitas, apuntes para pensar el presente socioambiental. Trabajo y Sociedad, 28, 281-307.

Romero, J. L. (1993). Breve historia de la Argentina. Buenos Aires: Huemul.

Ross Johnson, H. (1868). A long vacation in the Argentine Alps: or where to settle in the River Plate States. London: R. Bentley.

Salazar, G. (1984). Labradores, peones y proletarios. Formación y crisis de la sociedad popular chilena del siglo $X I X$. Santiago: Ediciones del Sur.

Salvatierra, E. (1965). Una explotación minera transhumante. En Actas del Primer Congreso de Historia de Catamarca. Tomo Segundo (pp. 199-202). Catamarca: Junta de Estudios Históricos de Catamarca.

Sánchez Gómez, J. (1989). De minería, metalúrgica y comercio de metales. La minería no férrica en el Reino de Castilla. 1450-1610. Salamanca: Universidad de Salamanca, Espańa.

Schickendantz, F. (1874 [1943]). Un viaje al cerro. En Federico Schickendantz. Homenaje a su memoria. Tucumán: Universidad Nacional de Tucumán.

Sierra Álvarez, J. (1984). De las utopías socialistas a las utopías patronales: para una genealogía de las disciplinas industriales paternalistas. Revista Española de Investigaciones Sociológicas, 26, 29-44.

Sierra Álvarez, J. (1985). Política de vivienda y disciplinas paternalistas industriales en Asturias. ERIA, 8, 61-71.

Sierra Álvarez, J. (1990). El obrero soñado. Ensayo sobre paternalismo industrial (Asturias, 1860-1917). Madrid: Siglo veintiuno editores.

Venegas Valdebenito, H. (2006). Atacama, de la crisis temporal a la crisis permanente. La minería del cobre en la segunda mitad del siglo XIX. Revista de Historia Social y de las Mentalidades, X(2), 75-103. 
Venegas Valdebenito, H. (2007). Auge y Caída de la Minería Chilena del Cobre. ¿Una Historia que se Repite? Contribuciones Científicas y Tecnológicas, 134, 6-19.

Venegas Valdebenito, H. (2014). Paternalismo industrial y control social. Las experiencias disciplinadoras en la minería del carbón en Chile, Lota y Coronel en la primera mitad del siglo XX. Amérique Latine Histoire et Mémoire. Les Cahiers ALHIM [en línea]. Recuperado de http://journals.openedition.org/ alhim/5099 (fecha de acceso 11.01.2018).

White, E. W. (1881). Cameos from the Silver Land, or the experiences of a young naturalist in the Argentine Republic. London: John van Voorst.

Zarankin, A. (2003). Arqueología de la arquitectura, modelando al individuo disciplinado en la sociedad capitalista. Revista de Arqueología Americana, 22, 25-39. 